Review article

\title{
Frameworks and tools for risk assessment of manufactured nanomaterials
}

\section{Danail Hristozov ${ }^{\mathrm{a}, *}$, Stefania Gottardo ${ }^{\mathrm{b}}$, Elena Semenzin ${ }^{\mathrm{a}}$, Agnes Oomen ${ }^{\mathrm{c}}$, Peter Bos ${ }^{\mathrm{c}}$, Willie Peijnenburg ${ }^{\mathrm{c}}$, Martie van Tongeren ${ }^{\mathrm{d}}$, Bernd Nowack ${ }^{\mathrm{e}}$, Neil Hunt ${ }^{\mathrm{f}}$, Andrea Brunelli ${ }^{\mathrm{a}}$, Janeck J. Scott-Fordsmand ${ }^{\mathrm{g}}$, Lang Tran ${ }^{\mathrm{d}}$, Antonio Marcomini ${ }^{\mathrm{a}}$}

a Department of Environmental Sciences, Informatics and Statistics, University Ca' Foscari of Venice, c/o PST Vega di Venezia - Via della Libertà 12, 30175 Marghera (VE), Italy

b European Commission's Joint Research Centre, Via E. Fermi 2749, 21027 Ispra, Italy

${ }^{c}$ National Institute of Public Health E' the Environment (RIVM), P.O. Box 1, 3720, BA, Bilthoven, The Netherlands

' Centre for Human Exposure Science, Institute of Occupational Medicine, Research Avenue, North, Riccarton, Edinburgh, EH14 4AP, Scotland

e EMPA-Swiss Federal Laboratories for Materials Science and Technology, Technology and Society Laboratory, CH-9014 St. Gallen, Switzerland

${ }^{\mathrm{f}}$ The REACH Centre, Lancaster Environment Centre, Lancaster University, Lancaster, Lancashire, LA1 4YQ United Kingdom

${ }^{g}$ Department of Bioscience-Terrestrial Ecology, Aarhus University, Vejlsøvej 25, 8600 Silkeborg, Denmark

\section{A R T I C L E I N F O}

\section{Article history:}

Received 28 May 2016

Received in revised form 20 July 2016

Accepted 28 July 2016

Available online 12 August 2016

\section{Keywords:}

Nanomaterials

Risk assessment

Frameworks

Tools

\begin{abstract}
A B S T R A C T
Commercialization of nanotechnologies entails a regulatory requirement for understanding their environmental, health and safety (EHS) risks. Today we face challenges to assess these risks, which emerge from uncertainties around the interactions of manufactured nanomaterials (MNs) with humans and the environment. In order to reduce these uncertainties, it is necessary to generate sound scientific data on hazard and exposure by means of relevant frameworks and tools. The development of such approaches to facilitate the risk assessment (RA) of MNs has become a dynamic area of research. The aim of this paper was to review and critically analyse these approaches against a set of relevant criteria. The analysis concluded that none of the reviewed frameworks were able to fulfill all evaluation criteria. Many of the existing modelling tools are designed to provide screeninglevel assessments rather than to support regulatory RA and risk management. Nevertheless, there is a tendency towards developing more quantitative, higher-tier models, capable of incorporating uncertainty into their analyses. There is also a trend towards developing validated experimental protocols for material identification and hazard testing, reproducible across laboratories. These tools could enable a shift from a costly case-by-case RA of MNs towards a targeted, flexible and efficient process, based on grouping and read-across strategies and compliant with the 3R (Replacement, Reduction, Refinement) principles. In order to facilitate this process, it is important to transform the current efforts on developing databases and computational models into creating an integrated data and tools infrastructure to support the risk assessment and management of MNs.
\end{abstract}

(c) 2016 Elsevier Ltd. All rights reserved.

Contents

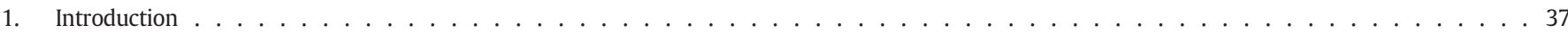

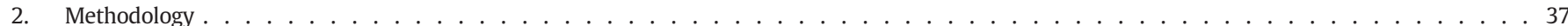

2.1. Critical review of peer-reviewed literature . . . . . . . . . . . . . . . . . . . . . . . . . . 37

2.2. Critical review of grey literature and information collected through a survey . . . . . . . . . . . . . . . . . . . . . . . . . . 37

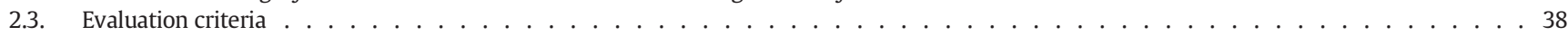

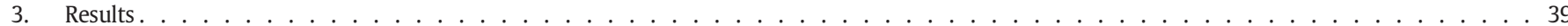

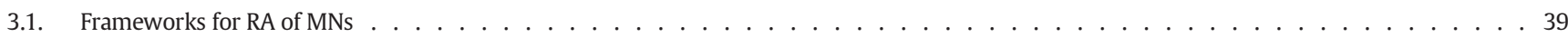

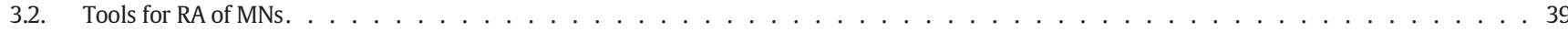

3.2.1. Control banding and risk screening tools . . . . . . . . . . . . . . . . . . . . . . . . . . . . . 39

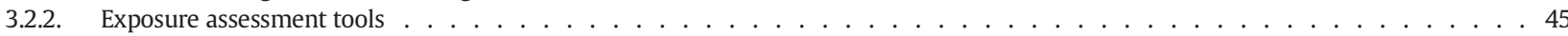

3.2.3. Hazard assessment tools . . . . . . . . . . . . . . . . . . . . . . . . . . . . . . . . 47

\footnotetext{
* Corresponding author.

E-mail addresses: danail.hristozov@unive.it (D. Hristozov), Stefania.GOTTARDO@ec.europa.eu (S. Gottardo), semenzin@unive.it (E. Semenzin), agnes.oomen@rivm.nl (A. Oomen), peter.bos@rivm.nl (P. Bos), willie.peijnenburg@rivm.nl (W. Peijnenburg), Martie.VanTongeren@iom-world.org (M. van Tongeren), nowack@empa.ch (B. Nowack),

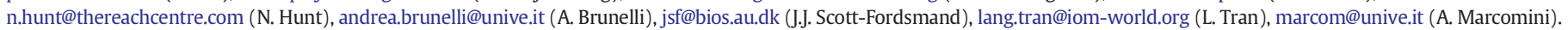


3.2.4. Risk assessment models . . . . . . . . . . . . . . . . . . . . . . . . . . . . 48

3.2.5. Physicochemical characterization tools. . . . . . . . . . . . . . . . . . . . . . . . . . . . . 48

3.2.6. Decision analytical tools . . . . . . . . . . . . . . . . . . . . . . . . . . 49

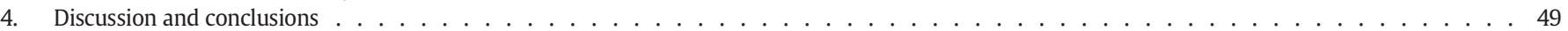

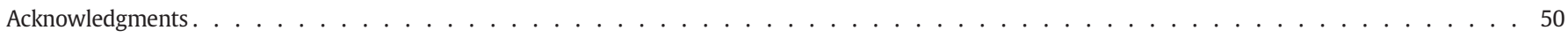

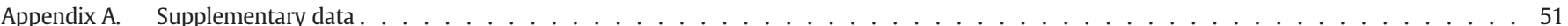

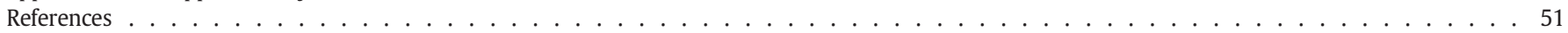

\section{Introduction}

Nanotechnology is one of the key emerging technologies identified in the European Union (EU) 2020 Strategy (European Commission, 2010). It has enormous potential to contribute to innovation and economic growth, which has fostered large investments in developing new industrial applications. However, current uncertainties around the Environmental, Health and Safety (EHS) risks of manufactured nanomaterials (MNs) have raised societal concerns about the adequacy of their regulation (Hristozov et al., 2012). In order to protect nanotechnology innovation sound scientific analysis of the MNs implications is required, taking into consideration all stages of their lifecycles.

The paradigm for Risk Assessment (RA) of chemicals is considered applicable to MNs if properly adapted to address the complexity associated with their identity, biological and environmental interactions (OECD and European Commission, 2012, EFSA, 2010, Stone et al., 2013). RA systematically applies scientific principles to estimate the probability that adverse human health or environmental effects could emerge from exposure to chemicals. The RA framework is composed of problem formulation, exposure assessment, hazard assessment, and risk characterization (Van Leeuwen and Vermeire, 2007). Specifically, the problem formulation is a systematic planning activity that sets the goals and the scope of the RA. The exposure assessment formulates exposure scenarios describing how a chemical is used by workers or consumers or how it is released into the environment. This is followed by estimations of exposure for one or more routes (i.e. inhalation, ingestion or dermal) or environmental compartments (e.g. water, sediment, soil) under the conditions of use described in the exposure scenarios. This may involve monitoring of indoor or outdoor concentrations by means of suitable analytical instruments and/or the estimation of the amount of the substance reaching humans or target environmental species by means of models. The hazard assessment involves the analysis of available data on (eco)toxicological effects in order to establish dose-response relationships. The risk characterization combines hazard and exposure to estimate risk.

There is a considerable volume of research and regulatory activity in the nanoEHS area, pointing to the fact that the (eco)toxicology and exposure data obtained for larger particles or for chemicals are generally useful and relevant to the evaluation of MNs hazards and risks (Donaldson and Poland, 2013). Nevertheless, the feasibility study of performing RA for MNs has identified serious gaps in our basic understanding of key nano-bio interactions, mechanisms of biological uptake, fate, distribution and bioaccumulation that have led to ambiguous, largely qualitative risk estimations based on expert judgments, which may fail to support proper risk management decision making (Hristozov et al., 2012). In order to fill the gaps, the academic community has been working together with industries and regulators for more than 10 years to develop frameworks and tools for RA of MNs. RA strategies have been reviewed in the past (Hristozov et al., 2012, Grieger et al., 2012, Som et al., 2013, Olson and Gurian, 2012) but the field of nanoEHS has rapidly developed and significant advancements have been made, which requires an update of these reviews.

In an attempt to avoid confusion in using the terms "framework", and "tool", we provide provisional definitions of them in the context of RA. A "framework" is a conceptual paradigm of how RA should be understood and performed. An example is the Chemical Safety Assessment (CSA) required by the REACH (Registration, Evaluation, Authorisation and Restriction) regulation. "Tools" are implements used to carry out particular functions or accomplish specific tasks (e.g. estimate exposure, build a dose-response curve). They can be for example specific models, experimental protocols or databases.

The main aim of this review paper is to analyse and evaluate the available frameworks and tools for RA of MNs against relevant criteria and discuss their strengths and weaknesses. This analysis had a strong focus on ongoing advancements in EU and U.S. research projects.

\section{Methodology}

\subsection{Critical review of peer-reviewed literature}

Published literature from 2000 to 2015 was searched for studies on RA of MNs by querying the Web of Science database with 10 keywords (nano, risk assessment, framework, methodology, method, tool, protocol, database, library, inventory). The search [string ts $=$ (nano* and (risk assessment) and (framework or methodology or method or tool or protocol) and (database or library or inventory)] retrieved 1749 records, out of which 46 papers described 6 frameworks and 14 tools relevant for the RA of MNs. In addition, the regulatory frameworks within the EU were considered. In order to critically review the identified approaches against a set of criteria, the relevant papers were divided into two categories: i) review or opinion papers; and ii) research papers that described specific frameworks or tools. Our critical appraisal focused on the second type of papers as they represent primary sources of information, while the opinion and review papers were only used to identify evaluation criteria and research trends.

\subsection{Critical review of grey literature and information collected through a survey}

The analysis of peer-reviewed literature was complemented by a review of results from relevant research projects. In order to identify those, we performed a search on CORDIS with the same keywords. This revealed a number of EU-funded projects, which are reported in the European Nanosafety Cluster Compendium. The scientific findings from these projects were assessed through a review of their interim reports and deliverables that were publically available or accessible to the authors. The identified frameworks and tools were evaluated against the criteria reported in Table 1.

In addition, a "google docs" online questionnaire was developed to survey organisations that are involved in developing nanoEHS tools. Potential participants and their contact information were identified from the European NanoSafety Cluster Compendium and personal communications with relevant individuals. The questionnaire (cf. Supplemental Information) covered several aspects characterising a tool: Scope, application domain, regulatory relevance, input data requirements, analytical methodology, expected outputs/results, case studies used for demonstration, stakeholders' involvement, and future research directions. It was distributed to representatives of the identified EU projects through the channels of the NanoSafety Cluster as well as to key centres in the 
Table 1

Frameworks and tools evaluation criteria.

\begin{tabular}{|c|c|c|}
\hline \multicolumn{3}{|l|}{ Frameworks } \\
\hline Criterion & Justification & Selected references \\
\hline Nano-specific requirements & $\begin{array}{l}\text { MNs present new physicochemical properties that may influence their kinetics, } \\
\text { bioavailability, toxicity and fate. Thus, these nano-specific parameters need to be } \\
\text { investigated during the exposure assessment and hazard assessment steps in order } \\
\text { to increase the level of certainty in the RA results (Stone et al., 2014). }\end{array}$ & $\begin{array}{l}\text { Environmental Defense and DuPont (2007), Pronk } \\
\text { et al. (2009), Bos et al. (2015), ECHA, JRC and RIVM } \\
\text { (2016) }\end{array}$ \\
\hline Lifecycle thinking & $\begin{array}{l}\text { It is important to assess the risks of MNs from a lifecycle perspective since the } \\
\text { characteristics of some MNs are likely to change significantly during their lifetime, } \\
\text { which would affect their hazard, exposure and risk. }\end{array}$ & $\begin{array}{l}\text { RENN and ROCO (2006), Shatkin (2008), SCENIHR } \\
\text { (2007), SCENIHR (2009), Bos et al. (2015), ECHA, } \\
\text { JRC and RIVM (2016), SCCS (2012) }\end{array}$ \\
\hline Pre-assessment phase & $\begin{array}{l}\text { Case-by-case RA of MNs can be very resource intensive. In order to focus the } \\
\text { assessment and avoid unnecessary testing costs, careful objective prioritization } \\
\text { and planning are needed, which should take place in the fundamental problem } \\
\text { formulation step. }\end{array}$ & $\begin{array}{l}\text { RENN and ROCO (2006), Shatkin (2008), Grieger et } \\
\text { al. (2012), Hristozov et al. (2012), Stone et al. } \\
\text { (2014), Bos et al. (2015) }\end{array}$ \\
\hline Exposure-driven approach & $\begin{array}{l}\text { It has been recognized that the testing of the currently available and still emerging } \\
\text { MNs in all their formulations is cost-prohibitive. This is why careful prioritization } \\
\text { of MNs is required to optimize testing efforts. We argue that it may be more } \\
\text { appropriate to conduct this prioritization following an exposure-driven approach. } \\
\text { This would allow us to exclude irrelevant exposure routes, leading to likely } \\
\text { waiving of the testing associated with them. In addition, it can support } \\
\text { prioritization of exposure scenarios in order to first focus on the most relevant } \\
\text { ones; if the exposure is negligible then the hazard data may be waived. }\end{array}$ & SCCS (2012), Stone et al. (2014), Bos et al. (2015) \\
\hline Iterative and adaptive structure & $\begin{array}{l}\text { In the next years more empirical data will appear for RA of MNs. Thus, there is } \\
\text { need for iterative and adaptive frameworks, allowing the rapid inclusion of new } \\
\text { information in the decision analytical process as it becomes available. }\end{array}$ & $\begin{array}{l}\text { RENN and ROCO (2006), SCENIHR (2007), SCENIHR } \\
\text { (2009), Stone et al. (2014), Bos et al. (2015) }\end{array}$ \\
\hline $\begin{array}{l}\text { Transparency of objectives and } \\
\text { communication with all involved } \\
\text { stakeholders }\end{array}$ & $\begin{array}{l}\text { It is important to consider the socio-economic, cultural and political context of the } \\
\text { RA process and dialogue with all relevant stakeholders involved in it. }\end{array}$ & $\begin{array}{l}\text { RENN and ROCO (2006), Hristozov et al. (2012), } \\
\text { Stone et al. (2014), Bos et al. (2015) }\end{array}$ \\
\hline Documented applications & $\begin{array}{l}\text { Documented applications are the best way to test a framework, confirm its } \\
\text { functionality and understand its strengths and limitations. }\end{array}$ & $\begin{array}{l}\text { Grieger et al. (2012), Hristozov et al. (2012), Bos et } \\
\text { al. (2015) }\end{array}$ \\
\hline $\begin{array}{l}\text { Allowing for/giving directions on } \\
\text { grouping and read-across of MNs }\end{array}$ & $\begin{array}{l}\text { Grouping and read-across of MNs can help to make optimal use of the available } \\
\text { data for RA. }\end{array}$ & (Oomen et al., 2015) \\
\hline \multicolumn{3}{|c|}{ 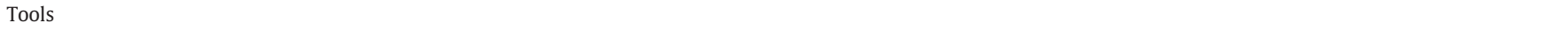 } \\
\hline Easy to use & $\begin{array}{l}\text { Tools that are easy to use do not require specific expertise for their application. } \\
\text { They are particularly relevant for Small and Medium Enterprises (SME) as those } \\
\text { companies often do not have staff with experience suited to apply sophisticated } \\
\text { protocols or models. }\end{array}$ & Hristozov et al. (2012), Subramanian et al. (2015) \\
\hline Quantitative information & $\begin{array}{l}\text { Tools that require quantitative input information to function cannot be easily } \\
\text { applied in data-poor situations, which reduces their overall applicability. }\end{array}$ & $\begin{array}{l}\text { Grieger et al. (2012), Hristozov et al. (2012), Bos et } \\
\text { al. (2015), Subramanian et al. (2015) }\end{array}$ \\
\hline Uncertainty analysis & $\begin{array}{l}\text { Clearly communicating the uncertainty and variability in modelling results } \\
\text { through sound uncertainty analysis greatly helps decision making. It could be } \\
\text { otherwise easily misled by overconfident communication of uncertain RA results. }\end{array}$ & $\begin{array}{l}\text { Hristozov et al. (2012), Stone et al. (2014), } \\
\text { Hristozov et al. (2016) }\end{array}$ \\
\hline Assessment tier & $\begin{array}{l}\text { The assessment tier criterion distinguishes the "screening-level" from the } \\
\text { "high-tier" tools. }\end{array}$ & Stone et al. (2014), Bos et al. (2015) \\
\hline Lifecycle thinking & $\begin{array}{l}\text { It is important to assess the risks of MNs from a lifecycle perspective since the } \\
\text { characteristics of some MNs are likely to change significantly during their lifetime, } \\
\text { which would affect their hazard, exposure and risk. }\end{array}$ & Stone et al. (2014), Bos et al. (2015) \\
\hline Documented applications & $\begin{array}{l}\text { Documented applications are the best way to test a tool, confirm its functionality } \\
\text { and understand its strengths and limitations. }\end{array}$ & $\begin{array}{l}\text { Grieger et al. (2012), Hristozov et al. (2012), Bos et } \\
\text { al. (2015) }\end{array}$ \\
\hline Transparency of application & $\begin{array}{l}\text { To make it easy it is for stakeholders to quickly comprehend how specific data } \\
\text { points and decision criteria influence decision making. }\end{array}$ & Subramanian et al. (2015) \\
\hline
\end{tabular}

U.S. via the EU-U.S. Communities of Research. The respondents were explicitly asked to fill in the questionnaire for one tool at the time. The results obtained from 29 organisations are presented in Table 4.

The analysis of "grey" documents from the research projects and the results of the survey identified 32 (sets of) tools, different from the ones derived from the peer-reviewed literature. This is not a discrepancy, but a difference caused by the fact that these tools are currently being developed and have not been published.

\subsection{Evaluation criteria}

The frameworks and tools identified from the review of literature and the information collected through the survey were evaluated against the criteria reported in Table 1. It is important to note that not all criteria fit to each tool and they cannot serve as a means for comparison as the tools have different goals in the overall RA approach, and they were developed in response to the needs of different stakeholders. Instead, these categories are to be used on a general information level to indicate some of the factors that the stakeholders should consider when seeking to perform RA of MNs. Therefore, we judge none of the frameworks or tools as superior or inferior to the others based on the evaluation criteria.

These criteria were derived from the state of the art literature, including the results of the major EU projects ITS-Nano and MARINA, which collectively involved the majority of European experts on RA of MNs from academia, industry and regulation to discuss such criteria in the context of developing intelligent testing and RA strategies for MNs (Stone et al., 2014, Bos et al., 2015, Oomen et al., 2014a). Some of these criteria consider methodological characteristics, such as "nanospecificity", "exposure-driven approach", "iterative and adaptive structure", "lifecycle thinking", "allowing for/giving directions on grouping and read-across", "uncertainty analysis". Others address the applicability of the approaches: e.g. "easy to use", "quantitative information", "documented applications", "transparency of application”, and "assessment tier". The selection of each criterion is justified in Table 1. 


\section{Results}

\subsection{Frameworks for RA of $M N S$}

Several frameworks of relevance for the RA of MNs have been proposed by regulatory bodies, non-governmental organisations, industry, and the scientific community. Table 2 lists their strengths and limitations from scientific perspective, while Table 3 evaluates them against the criteria listed in Table 1.

The frameworks are all based on the RA paradigm for chemicals and recommend a number of adaptations to address the complexity associated with MNs. Most of them stress the importance of the Problem Formulation as an essential prerequisite to the planning of the RA process in order to avoid unnecessary testing. Most of the frameworks allow for considering exposure aspects at the initial stage of the RA to inform (eco)toxicological investigations (Shatkin, 2008, RENN and ROCO, 2006, SCENIHR, 2007, 2009). This exposure-driven approach can potentially exclude irrelevant exposure routes, thus waiving unnecessary hazard testing in compliance with the 3Rs (Replacement, Reduction, Refinement) principles. In addition, it can insure that information gathering is optimised to address the most relevant exposure scenarios. The waiving of testing is in principle allowed under REACH (Annex XI) for any substance if the registrant can demonstrate absence of exposure or no significant exposure for all scenarios. In the European Food Safety Agency (EFSA) and Scientific Committee on Consumer Safety (SCCS) frameworks, it is more explicitly recommended that exposure considerations are anticipated to reduce testing for cases where the absence of exposure to MNs can be verified through demonstration of e.g. no migration of MNs into food/feed matrix from packaging, complete dissolution/degradation of the MNs in the food/feed matrix, or no translocation of the MNs across the skin. Despite the clear benefits of this approach, there are significant technical limitations to its application, which include challenges in detection and quantification of MNs in complex environmental and food matrices and the lack of validated exposure modelling tools (SCCS, 2012).

The data requirements of most frameworks are similar to the ones set in the "Guidance on Information Requirements and Chemical Safety Assessment" under REACH provided by the European Chemicals Agency (ECHA) and emphasize the need for comprehensive characterization of physicochemical properties (Pronk et al., 2009, SCENIHR, 2007, Environmental Defense and DuPont, 2007). Usually, the suggested properties to be determined include those listed by the OECD Working Party on Manufactured Nanomaterials (WPMN) (OECD, 2010). Specifically, SCENIHR recommend that adequate physicochemical characterization of MNs should study their transformations in different lifecycle stages, which requires investigation of different forms of the materials in different media (SCENIHR, 2007). More specifically, EFSA recommended that the physicochemical characterization of MNs is performed at five stages of the lifecycle: i) as manufactured (pristine), ii) as delivered for use in food/feed products, iii) as present in the food/feed matrix, iv) as used in toxicity testing, and v) as present in biological fluids and tissues. Similarly, SCCS recommends that physicochemical characterization of MNs is performed at three stages: i) as manufactured, ii) after addition to a cosmetic formulation, and iii) during toxicological investigations (SCCS, 2012).

The importance of thorough physicochemical characterization is also stressed by the ongoing efforts to establish criteria for grouping and read-across of MNs in order to reduce animal testing. This has become a dynamic area of research and several frameworks for grouping and read-across of MNs have been proposed (Arts et al., 2015a, RIVM, 2015, ECHA, JRC and RIVM, 2016, Gebel et al., 2014, Walser and Studer, 2015). These approaches are still rather conceptual and are not based on sufficient understanding of the interdependencies among the intrinsic and extrinsic properties of MNs and their observed adverse biological effects (Oomen et al., 2015). They were developed from either human health (Arts et al., 2015a) or environmental (RIVM, 2015) perspective and therefore differ significantly in the hierarchy of investigated physicochemical properties. Schemes developed from an occupational perspective often use "morphology" as a key grouping criterion, which was motivated by the well-established concern of inhalation of fibrous materials. In contrast, schemes developed from an environmental perspective assign more importance on properties such as hydrophobicity and surface charge. Both perspectives regard the reactivity and the shedding of heavy metal ions as important criteria.

\subsection{Tools for RA of MNs}

Forty eight tools to facilitate the RA of MNs were identified from the published literature and from projects (Table 4). They are grouped into types: Control banding, risk screening, occupational and consumer exposure, environmental fate and exposure, hazard assessment, physicochemical characterization, and decision support tools. Table 4 evaluates each tool against the criteria listed in Table 1.

\subsubsection{Control banding and risk screening tools}

Control banding is a family of qualitative and semi-quantitative models used to estimate hazard and exposure potentials of chemicals in order to assess the levels of precaution required to control their risks. Risk control is achieved through recommendation of appropriate Risk Management Measures (RMM) such as engineering and administrative controls as well as Personal Protective Equipment (PPE) (Paik et al., 2008). The hazard and exposure potentials are measured on normalized scales called "bands". These bands are typically plotted on a two-dimensional matrix, which results in establishing a control band associated to a specified level of precaution and a set of RMM to be implemented.

The control banding tools are always linked to specific occupational control measures and are developed and applied for workplace safety only. Risk screening is a similar approach, but it is also applicable for consumer and environmental RA.

3.2.1.1. Control banding tools. Control banding was proposed as an approach to implement the Precautionary Principle for risk management decision making in the cases when the available data and/or knowledge were insufficient for conducting regulatory RA of MNs (Maynard, 2007). Since then, several nano-specific control banding tools have been introduced. These tools were discussed by Brouwer (2012), whose review is updated in this paper. In regard to our evaluation criteria the control banding tools are easy to use and require minimum input information, which makes them suited for application by Small and Medium Enterprises (SMEs), which often do not have the resources and expertise to use more sophisticated tools.

The majority of the nano-specific control banding tools are semiquantitative. One example is the model proposed by Paik et al. (2008), which estimates "severity" of hazard and "probability" of exposure scores and plots them in a matrix to obtain one out of four levels of risk and associated RMM: Level 1: general ventilation; Level 2: fume hoods or local exhaust ventilation; Level 3: containment; Level 4: seek specialist advice. Similarly, the ANSES system is a semi-quantitative tool estimating bands based on sequential sets of questions, ordered in a decision tree (Ostiguy et al., 2010). The Stoffenmanager Nano combines semi-quantitative hazard information with qualitative estimates of inhalation exposure potential to assess risk (Duuren-Stuurman et al., 2011), as the exposure considerations in the tool are informed by a conceptual model described by Schneider et al. (2011).

In most cases the above tools consider nano-specific physicochemical characteristics in their estimations. In the ANSES system the hazard banding uses a classification scheme that is based on nano-relevant properties such as solubility and reactivity. Size is not considered, but aspect ratio is used to classify the bio-persistent fibres always in the highest hazard band. Stoffenmanager Nano distinguishes between single particles and agglomerates/aggregates and sets the following 
Table 2

Overview of the strengths and limitations of the available frameworks for RA of MNs.

\begin{tabular}{|c|c|c|c|}
\hline Framework & Structure & Strengths & Areas for improvement \\
\hline $\begin{array}{l}\text { Nanotechnology Risk } \\
\text { Governance (Renn and Roco, } \\
\text { 2006) }\end{array}$ & $\begin{array}{l}\text { 1. Pre-assessment (problem framing, early } \\
\text { warning and risk governance process } \\
\text { organization) } \\
\text { 2. Risk appraisal (Risk and Concern } \\
\text { assessments) } \\
\text { 3. Tolerability and acceptability judgement } \\
\text { 4. Risk management } \\
\text { 5. Risk communication }\end{array}$ & $\begin{array}{l}\text { Data sharing is encouraged } \\
\text { - Societal concerns and issues are taken into } \\
\text { account } \\
\text { - Risk communication is considered as an in- } \\
\text { tegral part of all stages of the risk gover- } \\
\text { nance process and crucial for the effective } \\
\text { linking the different components }\end{array}$ & $\begin{array}{l}\text { The framework specifies neither which } \\
\text { properties should be investigated, nor } \\
\text { which endpoints should be tested } \\
\text { - Uncertainties are identified but no specific } \\
\text { action is planned to deal with them }\end{array}$ \\
\hline $\begin{array}{l}\text { Nano Risk Framework } \\
\text { (Environmental Defense and } \\
\text { DuPont, 2007) }\end{array}$ & $\begin{array}{l}\text { 1. Describe material and application } \\
\text { 2. Profile lifecycle(s) } \\
\text { 3. Evaluate risks } \\
\text { 4. Assess Risk management } \\
\text { 5. Decide, document and act } \\
\text { 6. Review and adapt }\end{array}$ & $\begin{array}{l}\text { - It considers the potential exposure } \\
\text { throughout the whole lifecycle of the MNs } \\
\text { - The framework is iterative and adaptive. } \\
\text { The RA is expected to be updated when } \\
\text { new information become available and re- } \\
\text { views have to be planned when performing } \\
\text { the first RA. } \\
\text { - A template for reporting of the RA process } \\
\text { and communication of the risks is provided } \\
\text { (Output Worksheet) }\end{array}$ & $\begin{array}{l}\text { - Although identified, uncertainties are han- } \\
\text { dled in a qualitative way: the framework } \\
\text { points out areas of uncertainty and data } \\
\text { gaps and suggests a 'reasonable worst case' } \\
\text { approach. } \\
\text { - Some physicochemical properties relevant } \\
\text { for nano (e.g. dissolution, dustiness) recog- } \\
\text { nized as potential hazard descriptors are } \\
\text { not included in the base-set of required } \\
\text { information }\end{array}$ \\
\hline SCENIHR $(2007,2009)$ & $\begin{array}{l}\text { The framework is a decision tree approach, } \\
\text { composed of four stages: } \\
\text { 1. Assessment of need for exposure studies } \\
\text { 2. Exposure characterization } \\
\text { 3. Hazard identification, characterization } \\
\text { 4. Risk assessment }\end{array}$ & $\begin{array}{l}\text { - A set of relevant physicochemical proper- } \\
\text { ties are identified and suggested as re- } \\
\text { quired information when performing the } \\
\text { RA } \\
\text { - The proposed approach is exposure-driven } \\
\text { and the need for in vivo tests must be jus- } \\
\text { tified by in vitro or in silico investigations, } \\
\text { which adds cost efficiency and is in accor- } \\
\text { dance with the 3R principle }\end{array}$ & $\begin{array}{l}\text { The framework does not provide any spe- } \\
\text { cific detail on exposure and hazard assess- } \\
\text { ment strategies } \\
\text { - Life cycle perspective, transparency and } \\
\text { adaption of the assessment are listed as } \\
\text { features of the framework. However, there } \\
\text { are no documented applications to demon- } \\
\text { strate these characteristics. }\end{array}$ \\
\hline $\begin{array}{l}\text { Nano-Life Cycle Risk Analysis } \\
\text { (Nano-LCRA) (Shatkin, 2008) }\end{array}$ & $\begin{array}{l}\text { The framework consists of ten steps: } \\
\text { 1. Description of the lifecycle of the } \\
\text { product } \\
\text { 2. Identification of the materials and as- } \\
\text { sess potential hazards in each lifecycle } \\
\text { stage } \\
\text { 3. Qualitative exposure assessment for } \\
\text { materials at each lifecycle stage } \\
\text { 4. Identification of stages of lifecycle when } \\
\text { exposure may occur } \\
\text { 5. Evaluation of the potential human and } \\
\text { non-human toxicity at key lifecycle } \\
\text { stages } \\
\text { 6. Analysis of risk potential } \\
\text { 7. Identification of key uncertainties and } \\
\text { data gaps } \\
\text { 8. Development of risk mitigation/- } \\
\text { management strategies } \\
\text { 9. Gathering of additional information } \\
\text { 10. Reiteration of the process. }\end{array}$ & $\begin{array}{l}\text { - Nano LCRA is a screening-level framework } \\
\text { that can be applied when little information } \\
\text { is available } \\
\text { - "Mini" hazard and exposure assessments } \\
\text { are conducted for each step of the lifecycle } \\
\text { and further investigation (effects assess- } \\
\text { ment) is performed only for the steps } \\
\text { where exposure occurs, allowing saving } \\
\text { time and resources } \\
\text { There is a step of the framework focused on } \\
\text { the evaluation of the level of confidence in } \\
\text { the assessment. However, although key } \\
\text { sources of uncertainty are identified, the } \\
\text { framework does not suggest any specific } \\
\text { approach for their management }\end{array}$ & $\begin{array}{l}\text { This framework does not give any indica- } \\
\text { tion about the specific endpoints to be in- } \\
\text { vestigated } \\
\text { - Although the risk management is defined } \\
\text { by the author as adaptive and transparent, } \\
\text { there is no documented application to } \\
\text { demonstrate this nature of the framework }\end{array}$ \\
\hline $\begin{array}{l}\text { Nanomaterials under REACH } \\
\text { (Pronk et al., 2009) }\end{array}$ & $\begin{array}{l}\text { The framework represents a revision of the } \\
\text { approach for RA of chemicals applied under } \\
\text { REACH }\end{array}$ & $\begin{array}{l}\text { - A "base-set" of nano-specific information is } \\
\text { required in the first phase of the process } \\
\text { - The nature of the conventional RA ap- } \\
\text { proach ensures the inclusion of the princi- } \\
\text { ples of transparency and precaution in the } \\
\text { decision making process } \\
\text { - Exposure is considered throughout the } \\
\text { whole like cycle of the MNs }\end{array}$ & $\begin{array}{l}\text { The framework underlines all the signifi- } \\
\text { cant uncertainties related to the RA of } \\
\text { nanomaterials, but a comprehensive strat- } \\
\text { egy to reduce and/or manage these uncer- } \\
\text { tainties is not proposed }\end{array}$ \\
\hline $\begin{array}{l}\text { Comprehensive Environmental } \\
\text { Assessment (CEA) (Davis et al., } \\
\text { 2010) }\end{array}$ & $\begin{array}{l}\text { 1. Life cycle stages } \\
\text { 2. Environmental pathways, i.e. identifica- } \\
\text { tion of the media where the nanoparti- } \\
\text { cles can spread } \\
\text { 3. Transport and transformation } \\
\text { 4. Exposure via inhalation, ingestion or } \\
\text { dermal absorption } \\
\text { 5. Effects (health and ecological) }\end{array}$ & $\begin{array}{l}\text { - It considers the RA of a nanomaterial from a } \\
\text { lifecycle perspective } \\
\text { - It takes into account the variability of the } \\
\text { properties of nanomaterials by considering } \\
\text { the formation of manufacturing process } \\
\text { by-products and environmental transfor- } \\
\text { mation products } \\
\text { - Indications on some (but not all) properties } \\
\text { relevant for the characterization of } \\
\text { nanomaterials are provided }\end{array}$ & $\begin{array}{l}\text { - It does not provide any specific procedure } \\
\text { to deal with uncertainties } \\
\text { - Although adaptability and transparency are } \\
\text { indicated as milestones of the framework, } \\
\text { these characteristics are not demonstrated } \\
\text { in any documented application }\end{array}$ \\
\hline $\begin{array}{l}\text { MARINA Framework (Bos et al., } \\
\text { 2015) }\end{array}$ & $\begin{array}{l}\text { The framework is composed of two } \\
\text { subsequent phases and four pillars which } \\
\text { are closely linked. The two phases include: }\end{array}$ & $\begin{array}{l}\text { - Nano-specific requirements } \\
\text { - Life cycle thinking } \\
\text { - Pre-assessment phase } \\
\text { - Exposure driven approach }\end{array}$ & $\begin{array}{l}\text { - Still conceptual } \\
\text { - Has not been tested in real case studies yet. }\end{array}$ \\
\hline
\end{tabular}


Table 2 (continued)

\begin{tabular}{|c|c|c|c|}
\hline Framework & Structure & Strengths & Areas for improvement \\
\hline & $\begin{array}{l}\text { 1. Problem framing, and } \\
\text { 2. Risk assessment consisting of a refined } \\
\text { assessment starting from the Phase } 1 \\
\text { outcome. } \\
\text { Three information-gathering pillars and a } \\
\text { risk characterization pillar are situated } \\
\text { across both phases. Each of these four pillars } \\
\text { can be regarded as a toolbox containing } \\
\text { data-generating tools (information-- } \\
\text { gathering pillars) or risk assessment tools } \\
\text { (risk characterization pillar) that range from } \\
\text { relatively simple to very complex. }\end{array}$ & $\begin{array}{l}\text { - Iterative/adaptive structure } \\
\text { - Transparency/Communication }\end{array}$ & \\
\hline $\begin{array}{l}\text { ECHA/RIVM/JRC read-across and } \\
\text { grouping framework for } \\
\text { nanomaterials (ECHA, JRC and } \\
\text { RIVM, 2016) }\end{array}$ & $\begin{array}{l}\text { The strategy for using data between } \\
\text { nanoforms consists of } 6 \text { steps: } \\
\text { 1. Identification of the nanoforms } \\
\text { 2. Initial grouping of the nanoforms } \\
\text { 3. Identification of avalable data and data } \\
\text { gaps } \\
\text { 4. Identification of potential source } \\
\text { nanoforms } \\
\text { 5. Substantiate hypothesisAssess new data }\end{array}$ & $\begin{array}{l}\text { - Provides a structured approach to guide } \\
\text { registrants and regulators on how to apply } \\
\text { grouping and read-across concepts to } \\
\text { nanoforms } \\
\text { - Compliant with the REACH requirements } \\
\text { for CSA } \\
\text { - Can help to reduce testing } \\
\text { - Considers data quality in the grouping and } \\
\text { read-across processes }\end{array}$ & $\begin{array}{l}\text { - Strongly depends on data on physicochem- } \\
\text { ical parameters of each nanoform, which } \\
\text { are often unavailable } \\
\text { - Requires high quality of the data for moni- } \\
\text { toring of physicochemical parameters dur- } \\
\text { ing testing, which is difficult to ensure or } \\
\text { derive from the published literature } \\
\text { - Limited to read-across for hazard endpoints }\end{array}$ \\
\hline $\begin{array}{l}\text { ECETOC decision analytical } \\
\text { framework to facilitate the } \\
\text { grouping of nanomaterials } \\
\text { (DF4nanoGrouping) (Arts et } \\
\text { al., 2015a) }\end{array}$ & $\begin{array}{l}\text { DF4nanoGrouping consists of } 3 \text { tiers to } \\
\text { assign MNs to } 4 \text { main groups: } \\
\text { 1. Soluble MNs } \\
\text { 2. Biopersistent high aspect ratio MNs } \\
\text { 3. Passive MNs, and } \\
\text { 4. Active MNs }\end{array}$ & $\begin{array}{l}\text { - Covers all relevant aspects of MNs life cy- } \\
\text { cles and biological pathways such as intrin- } \\
\text { sic material and system-dependent } \\
\text { properties, biopersistence, uptake and } \\
\text { biodistribution, cellular and apical toxic ef- } \\
\text { fects } \\
\text { - Use, release and route of exposure are ap- } \\
\text { plied as "qualifiers" in order to determine if } \\
\text { MNs can be released from a product matrix } \\
\text { - Groups MNs by their specific modes of ac- } \\
\text { tion that result in apical toxic effects }\end{array}$ & $\begin{array}{l}\text { - Still does not cover environmental scenari- } \\
\text { os } \\
\text { - The decision analytical framework is still } \\
\text { rather conceptual }\end{array}$ \\
\hline $\begin{array}{l}\text { ECHA Guidance on RA of MNs } \\
\text { under REACH (ECHA, 2012c, } \\
\text { ECHA, 2012b, ECHA, 2012d, } \\
\text { ECHA, 2012e, ECHA, 2012f, } \\
\text { ECHA, 2012a) }\end{array}$ & $\begin{array}{l}\text { 1. Human health hazard assessment } \\
\text { 2. Human health hazard assessment of } \\
\text { physicochemical properties } \\
\text { 3. Environmental hazard assessment } \\
\text { 4. PBT and vPvB assessment } \\
\text { 5. Exposure assessment } \\
\text { 6. Risk characterization }\end{array}$ & $\begin{array}{l}\text { - It implements the regulatory RA of } \\
\text { chemicals to MNs and provides guidance } \\
\text { on the adaptations } \\
\text { - It provides guidance on physicochemical } \\
\text { parameters and analytical methods } \\
\text { - It provides advice on e.g. test sample prep- } \\
\text { aration and interference with specific } \\
\text { assays, applicability of non-testing } \\
\text { methods, dose metrics, extrapolation and } \\
\text { assessment factors is provided } \\
\text { - It covers all uses of the MNs along the } \\
\text { lifecycle (from production to end of life) } \\
\text { - Grouping, read-across, and exposure-based } \\
\text { waiving are in principle applicable }\end{array}$ & $\begin{array}{l}\text { - No legal definition of 'nanomaterial' (MNs } \\
\text { implicitly covered by the REACH definition } \\
\text { of 'substance') } \\
\text { - Nano-specific information requirements } \\
\text { are not in the legal text but in guidance } \\
\text { - It provides guidance on how to partially } \\
\text { address criticalities and uncertainties but } \\
\text { not on their quantification }\end{array}$ \\
\hline $\begin{array}{l}\text { EFSA Guidance on RA of MN in } \\
\text { the food and feed chain (EFSA, } \\
\text { 2011) }\end{array}$ & $\begin{array}{l}\text { The framework is a decision tree based on } \\
\text { the following steps: } \\
\text { 1. Physicochemical characterization } \\
\text { 2. Determine exposure scenarios } \\
\text { 3. Read-across to non-nanoform and/or } \\
\text { specific testing } \\
\text { 4. Hazard identification and hazard } \\
\text { characterization } \\
\text { 5. Exposure assessment } \\
\text { 6. Risk characterization }\end{array}$ & $\begin{array}{l}\text { - Legal definition of 'engineered } \\
\text { nanomaterial' } \\
\text { - It implements the regulatory RA of } \\
\text { chemicals to MNs and provides guidance } \\
\text { on the adaptations } \\
\text { - It provides list of physicochemical parame- } \\
\text { ters } \\
\text { - It recommends physicochemical character- } \\
\text { ization of MNs in five stages: as } \\
\text { manufactured, as delivered for use in } \\
\text { products, as present in food/feed matrix, as } \\
\text { used in toxicity testing, as present in bio- } \\
\text { logical fluids and tissues } \\
\text { - It allows for reduced testing when no ex- } \\
\text { posure to MNs is verified (no migration } \\
\text { from packaging, complete degradation/- } \\
\text { dissolution) } \\
\text { - It provides guidance on six different toxici- } \\
\text { ty testing strategies } \\
\text { - Read-across to non-nanoform is suggested } \\
\text { in some cases }\end{array}$ & $\begin{array}{l}\text { - Nano-specific information requirements } \\
\text { are not in the legal text but in guidance } \\
\text { - It provides guidance on how to partially } \\
\text { address criticalities and uncertainties but } \\
\text { not on their quantification }\end{array}$ \\
\hline $\begin{array}{l}\text { SCCS Guidance on RA of MN in } \\
\text { cosmetics products (SCCS, } \\
\text { 2012) }\end{array}$ & $\begin{array}{l}\text { 1. Physicochemical characterization } \\
\text { 2. Exposure assessment considering possi- } \\
\text { ble routes } \\
\text { 3. Hazard identification and dose-response } \\
\text { characterization }\end{array}$ & $\begin{array}{l}\text { - Legal definition of 'nanomaterial' } \\
\text { - It implements the regulatory RA of } \\
\text { chemicals to MNs and provides guidance } \\
\text { on the adaptations } \\
\text { - It provides list of physicochemical parame- } \\
\text { ters } \\
\text { - It recommends physicochemical character- } \\
\text { ization of MNs in three stages: as }\end{array}$ & $\begin{array}{l}\text { - Nano-specific information requirements } \\
\text { are not in the legal text but in guidance } \\
\text { - It provides guidance on how to partially } \\
\text { address criticalities and uncertainties but } \\
\text { not on their quantification }\end{array}$ \\
\hline
\end{tabular}


Table 2 (continued)

\begin{tabular}{|c|c|c|c|}
\hline Framework & Structure & Strengths & Areas for improvement \\
\hline & 4. Risk assessment & $\begin{array}{l}\text { manufactured, as present in cosmetic } \\
\text { formulation, as used in toxicity testing, } \\
\text { RA of MNs may be driven by exposure } \\
\text { considerations (translocation, systemic } \\
\text { absorption) } \\
\text { It allows for use of validated alternative } \\
\text { methods for hazard assessment of MNs }\end{array}$ & \\
\hline
\end{tabular}

REACH Annexes laying out the standard information requirements for registrants are currently under review for nanomaterials by the European Commission.

nano-relevance criteria: i) particles are not (water) soluble; ii) they are synthetically produced and not unintentionally released from e.g. incomplete combustion; iii) the size of the primary particles is smaller than $100 \mathrm{~nm}$ and/or the specific surface area of nanopowders is larger than $60 \mathrm{~m}^{2} / \mathrm{g}$ (Duuren-Stuurman et al., 2011).

Out of the reviewed tools only Paik et al. (2008) and Stoffenmanager Nano were tested in real case studies. Paik et al. (2008) assessed four representative MNs activities for their risk level and potential control schemes, while Zalk et al. (2009) used the same tool to address twenty-seven real industrial activities. Stoffenmanager Nano was tested in some of the industrial workplaces studied in the EU-funded SCAFFOLD project. Overall, the tools performed as expected, but the uncertainties in their application were not addressed.
3.2.1.2. Risk screening tools. The risk screening tools are also easy to use, they have relatively low data requirements and the majority of them can cover more than one lifecycle stages (e.g. occupational scenarios in both the production and end-of-life stages). Most of them are qualitative or semi-quantitative, but also quantitative risk scoring procedures were developed. Specifically, the Precautionary Matrix for Synthetic Nanomaterials (Höck et al., 2010) is a semiquantitative approach designed to estimate effects, exposure, nano-relevance, and specific framework conditions in workplace, consumer and environmental settings. Scores are assigned to several criteria and they are aggregated into a "precautionary need" index. The Tool for MNs-Application Pair Risk Ranking (TEARR) (Grieger et al., 2015) is another semi-quantitative approach developed by the U.S. Army Corps of Engineers. It uses a variety of input

Table 3

Evaluation of the selected nanospecific frameworks according to 6 criteria relevant for RA. $-=$ Criterion not fulfilled; $+=$ Criterion fulfilled; $\pm=$ Criterion not fully fulfilled.

\begin{tabular}{|c|c|c|c|c|c|c|c|c|}
\hline \multirow[b]{2}{*}{ Framework } & \multicolumn{7}{|l|}{ Criteria } & \multirow{2}{*}{$\begin{array}{l}\text { Allowing } \\
\text { for/giving } \\
\text { directions on } \\
\text { grouping and } \\
\text { read-across }\end{array}$} \\
\hline & $\begin{array}{l}\text { Nano-specific } \\
\text { requirements }\end{array}$ & $\begin{array}{l}\text { Life } \\
\text { cycle } \\
\text { thinking }\end{array}$ & $\begin{array}{l}\text { Pre-assessment } \\
\text { phase }\end{array}$ & $\begin{array}{l}\text { Exposure } \\
\text { driven } \\
\text { approach }\end{array}$ & $\begin{array}{l}\text { Iterative/adaptive } \\
\text { structure }\end{array}$ & Transparency/Communication & $\begin{array}{l}\text { Documented } \\
\text { applications }\end{array}$ & \\
\hline $\begin{array}{l}\text { Nanotechnology Risk Governance } \\
\text { (RENN and ROCO, 2006) }\end{array}$ & - & \pm & + & + & \pm & \pm & \pm & - \\
\hline $\begin{array}{l}\text { Nano Risk Framework } \\
\text { (Environmental Defense and } \\
\text { DuPont, 2007) }\end{array}$ & + & \pm & + & \pm & + & + & \pm & - \\
\hline SCENIHR $(2007,2009)$ & + & \pm & + & + & \pm & \pm & - & - \\
\hline $\begin{array}{l}\text { Nano-Life Cycle Risk Analysis } \\
\text { (Nano-LCRA) (Shatkin, 2008) }\end{array}$ & - & \pm & + & + & \pm & \pm & \pm & - \\
\hline $\begin{array}{l}\text { Nanomaterials under REACH } \\
\text { (Pronk et al., 2009) }\end{array}$ & + & + & + & - & \pm & \pm & \pm & - \\
\hline $\begin{array}{l}\text { Comprehensive Environmental } \\
\text { Assessment (CEA) (Davis et al., } \\
\text { 2010) }\end{array}$ & - & + & \pm & - & \pm & + & + & - \\
\hline $\begin{array}{l}\text { MARINA Framework (Bos et al., } \\
\text { 2015) }\end{array}$ & + & + & + & + & + & + & - & + \\
\hline $\begin{array}{l}\text { ECHA/RIVM/JRC read-across and } \\
\text { grouping framework for } \\
\text { nanomaterials (ECHA, JRC and } \\
\text { RIVM, 2016) }\end{array}$ & + & \pm & - & - & \pm & + & - & + \\
\hline $\begin{array}{l}\text { ECETOC decision analytical } \\
\text { framework to facilitate the } \\
\text { grouping of nanomaterials } \\
\text { (DF4nanoGrouping) (Arts et al., } \\
\text { 2015a) }\end{array}$ & + & + & - & - & \pm & + & - & + \\
\hline $\begin{array}{l}\text { ECHA Guidance on RA of MNs } \\
\text { under REACH (ECHA, 2012c, } \\
\text { ECHA, 2012b, ECHA, 2012d, } \\
\text { ECHA, 2012e, ECHA, 2012f, } \\
\text { ECHA, 2012a) }\end{array}$ & + & + & + & \pm & \pm & + & \pm & \pm \\
\hline $\begin{array}{l}\text { EFSA Guidance on RA of MNs in } \\
\text { the food and feed chain (EFSA, } \\
\text { 2011) }\end{array}$ & + & + & + & + & \pm & + & \pm & \pm \\
\hline $\begin{array}{l}\text { SCCS Guidance on RA of MNs in } \\
\text { cosmetics products (SCCS, } \\
\text { 2012) }\end{array}$ & + & + & + & + & \pm & + & \pm & \pm \\
\hline
\end{tabular}


Table 4

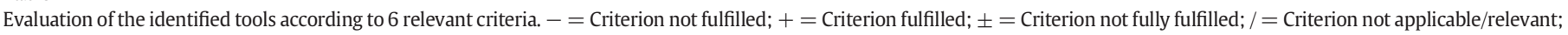
$(\mathrm{P})=$ Tool under development in an on-going project.

\begin{tabular}{|c|c|c|c|c|c|c|c|c|}
\hline \multirow[b]{2}{*}{ Tool } & \multicolumn{8}{|l|}{ Criteria } \\
\hline & Type of tool & $\begin{array}{l}\text { Protocol } \\
\text { (P)/Modelling } \\
\text { (M)/Database } \\
\text { (D) }\end{array}$ & $\begin{array}{l}\text { Easy } \\
\text { to } \\
\text { use }\end{array}$ & $\begin{array}{l}\text { Quantitative } \\
\text { estimation/information }\end{array}$ & $\begin{array}{l}\text { Uncertainty } \\
\text { analysis }\end{array}$ & $\begin{array}{l}\text { Life cycle } \\
\text { perspective }\end{array}$ & $\begin{array}{l}\text { Documented } \\
\text { applications }\end{array}$ & $\begin{array}{l}\text { Assessment } \\
\text { tier }\end{array}$ \\
\hline Maynard (2007) & Control banding & M & + & - & - & - & - & Low \\
\hline $\begin{array}{l}\text { Nanomaterials Control Banding Tool (Paik et } \\
\text { al., 2008) (Zalk et al., 2009) }\end{array}$ & Control banding & M & + & - & - & - & - & Low \\
\hline $\begin{array}{l}\text { ANSES Control Banding Tool (Ostiguy et al., } \\
\text { 2010) }\end{array}$ & Control banding & M & \pm & - & - & - & + & Low \\
\hline $\begin{array}{l}\text { Stoffenmanager Nano (Duuren-Stuurman et } \\
\text { al., 2011) }\end{array}$ & Control banding & M & + & - & - & - & + & Low \\
\hline $\begin{array}{l}\text { Precautionary Matrix for Synthetic } \\
\text { Nanomaterials (Höck et al., 2010) }\end{array}$ & $\begin{array}{l}\text { Human and } \\
\text { environmental risk } \\
\text { screening }\end{array}$ & M & + & - & \pm & \pm & - & Low \\
\hline $\begin{array}{l}\text { Multi-criteria Acceptability Analysis } \\
\text { (SMAA-TRI) Tool (Tervonen et al., 2009) }\end{array}$ & $\begin{array}{l}\text { Human and } \\
\text { environmental risk } \\
\text { screening }\end{array}$ & M & - & + & + & \pm & \pm & Low \\
\hline $\begin{array}{l}\text { (P) Tool for ENM-Application Pair Risk } \\
\text { Ranking (TEARR) (Grieger et al., 2015) }\end{array}$ & Human risk screening & $\mathrm{P} / \mathrm{M}$ & + & \pm & - & \pm & - & Low \\
\hline Hristozov et al. (2014) & $\begin{array}{l}\text { Human hazard } \\
\text { screening }\end{array}$ & M & - & + & + & \pm & + & Low \\
\hline Hristozov et al. (2014) & $\begin{array}{l}\text { Occupational exposure } \\
\text { screening }\end{array}$ & M & - & + & + & \pm & + & Low \\
\hline Hristozov et al. (2016) & Human risk screening & M & - & + & + & \pm & + & Low \\
\hline $\begin{array}{l}\text { (P) MARINA Species Sensitivity } \\
\text { Distributions (SSD) Tool (Semenzin et al., } \\
\text { 2015) }\end{array}$ & $\begin{array}{l}\text { Environmental risk } \\
\text { assessment }\end{array}$ & M & + & + & + & - & + & Low/high \\
\hline (P) NanoSafer (Jensen et al., 2013) & $\begin{array}{l}\text { Occupational exposure } \\
\text { assessment }\end{array}$ & M & + & + & - & + & + & Low \\
\hline NanoRiskCat (Hansen et al., 2013) & $\begin{array}{l}\text { Consumer exposure } \\
\text { assessment }\end{array}$ & M & + & - & - & - & + & Low \\
\hline $\begin{array}{l}\text { Advanced REACH Tool (ART) (Fransman et } \\
\text { al., 2009) }\end{array}$ & $\begin{array}{l}\text { Occupational exposure } \\
\text { assessment }\end{array}$ & M & + & + & - & - & + & High \\
\hline $\begin{array}{l}\text { (P) Dermal Advanced REACH Tool (DART) } \\
\text { (Gorman et al., 2012) }\end{array}$ & $\begin{array}{l}\text { Occupational/consumer } \\
\text { exposure assessment }\end{array}$ & M & + & + & - & - & - & Low/high \\
\hline $\begin{array}{l}\text { (P) SUN tiered occupational and consumer } \\
\text { exposure model } \\
\text { (www.sun-fp7.eu/) }\end{array}$ & $\begin{array}{l}\text { Occupational/consumer } \\
\text { exposure assessment }\end{array}$ & M & + & \pm & + & - & + & Low/high \\
\hline (P) MARINA & $\begin{array}{l}\text { Occupational exposure } \\
\text { experiments }\end{array}$ & $\mathrm{P}$ & - & + & / & / & + & Low/high \\
\hline Boxall et al. (2008) & $\begin{array}{l}\text { Environmental } \\
\text { fate/exposure } \\
\text { assessment }\end{array}$ & M & \pm & + & - & \pm & + & Low \\
\hline Mueller and Nowack (2008) & $\begin{array}{l}\text { Environmental } \\
\text { fate/exposure } \\
\text { assessment }\end{array}$ & M & - & + & \pm & + & + & Low \\
\hline $\begin{array}{l}\text { Stochastic Materials Flow model (Gottschalk } \\
\text { et al., 2010a, 2010b, Sun et al., 2014, } \\
\text { Gottschalk et al., 2009, Gottschalk et al., } \\
\text { 2013, Gottschalk et al., 2011) }\end{array}$ & $\begin{array}{l}\text { Environmental } \\
\text { fate/exposure } \\
\text { assessment }\end{array}$ & M & - & + & + & + & + & Low/high \\
\hline $\begin{array}{l}\text { (P) CEINT (DALE et al., 2015) } \\
\text { (http://www.ceint.duke.edu/) }\end{array}$ & $\begin{array}{l}\text { Environmental } \\
\text { fate/exposure } \\
\text { assessment }\end{array}$ & M & - & + & - & + & + & Low/high \\
\hline $\begin{array}{l}\text { (P) CEINT/TINE (Dale et al., 2013) } \\
\text { (http://www.ceint.duke.edu/) }\end{array}$ & $\begin{array}{l}\text { Environmental } \\
\text { fate/exposure } \\
\text { assessment }\end{array}$ & M & - & + & - & + & + & High \\
\hline Ardvisson et al. (2011) & $\begin{array}{l}\text { Environmental } \\
\text { fate/exposure } \\
\text { assessment }\end{array}$ & M & - & + & - & l & - & High \\
\hline Quik et al. (2014) & $\begin{array}{l}\text { Environmental } \\
\text { fate/exposure } \\
\text { assessment }\end{array}$ & M & - & + & - & l & - & High \\
\hline O'brien and Cummins (2011) & $\begin{array}{l}\text { Environmental } \\
\text { fate/exposure } \\
\text { assessment }\end{array}$ & M & - & - & + & + & \pm & Low \\
\hline Money et al. (2012) & $\begin{array}{l}\text { Environmental } \\
\text { fate/exposure } \\
\text { assessment }\end{array}$ & M & - & + & + & / & - & Low \\
\hline SimpleBox4Nano (Meesters et al., 2014) & $\begin{array}{l}\text { Environmental } \\
\text { fate/exposure } \\
\text { assessment }\end{array}$ & M & - & + & - & + & + & Low \\
\hline $\begin{array}{l}\text { (P) MARINA (Tuoriniemi et al., 2014, } \\
\text { Cornelis and Hassellov, 2014) }\end{array}$ & $\begin{array}{l}\text { Environmental } \\
\text { behaviour, fate and } \\
\text { exposure experiments }\end{array}$ & $\mathrm{P}$ & - & + & / & / & + & High \\
\hline
\end{tabular}




\begin{tabular}{|c|c|c|c|c|c|c|c|c|}
\hline \multirow[b]{2}{*}{ Tool } & \multicolumn{8}{|l|}{ Criteria } \\
\hline & Type of tool & $\begin{array}{l}\text { Protocol } \\
\text { (P)/Modelling } \\
\text { (M)/Database } \\
\text { (D) }\end{array}$ & $\begin{array}{l}\text { Easy } \\
\text { to } \\
\text { use }\end{array}$ & $\begin{array}{l}\text { Quantitative } \\
\text { estimation/information }\end{array}$ & $\begin{array}{l}\text { Uncertainty } \\
\text { analysis }\end{array}$ & $\begin{array}{l}\text { Life cycle } \\
\text { perspective }\end{array}$ & $\begin{array}{l}\text { Documented } \\
\text { applications }\end{array}$ & $\begin{array}{l}\text { Assessment } \\
\text { tier }\end{array}$ \\
\hline (P) MARINA (Kühnel and Nickel, 2014) & $\begin{array}{l}\text { Environmental } \\
\text { behaviour, fate and } \\
\text { exposure experiments }\end{array}$ & $\mathrm{P}$ & - & + & / & / & + & Low \\
\hline $\begin{array}{l}\text { (P) NANEX/MARINA } \\
\text { (www.nanex-project.eu/) }\end{array}$ & $\begin{array}{l}\text { Exposure scenario } \\
\text { library, occupational } \\
\text { setting }\end{array}$ & $\mathrm{D}$ & + & \pm & / & - & / & Low \\
\hline (P) NECID (http://www.perosh.eu/) & $\begin{array}{l}\text { Exposure scenario } \\
\text { database, occupational } \\
\text { setting }\end{array}$ & $\mathrm{D}$ & + & \pm & / & + & / & Low/high \\
\hline $\begin{array}{l}\text { Physiologically-based pharmacokinetic } \\
\text { (PBPK) models (Riviere, 2014) }\end{array}$ & $\begin{array}{l}\text { Kinetic models for } \\
\text { internal exposure } \\
\text { assessment }\end{array}$ & M & - & + & - & - & + & Low/high \\
\hline $\begin{array}{l}\text { Short Term Inhalation Studies (Klein et al., } \\
\text { 2012) }\end{array}$ & $\begin{array}{l}\text { In vivolkinetic tools for } \\
\text { human exposure and } \\
\text { hazard assessment }\end{array}$ & $\mathrm{P}$ & - & + & l & / & + & Low/high \\
\hline (P) SUN Short Term Oral Studies & $\begin{array}{l}\text { In vivolkinetic tools for } \\
\text { human exposure and } \\
\text { hazard assessment }\end{array}$ & $\mathrm{P}$ & - & + & / & / & + & Low/high \\
\hline $\begin{array}{l}\text { (P) STAR (Yokel et al., 2009, Yokel et al., } \\
\text { 2012, Hardas et al., 2010, Dan et al., 2011) }\end{array}$ & $\begin{array}{l}\text { In vivolkinetic tools for } \\
\text { human exposure and } \\
\text { hazard assessment }\end{array}$ & $\mathrm{P}$ & - & + & / & / & + & Low/high \\
\hline $\begin{array}{l}\text { (P) MARINA (Lammel et al., 2013, Lammel } \\
\text { and Navas, 2014) }\end{array}$ & $\begin{array}{l}\text { In vitro and in vivo } \\
\text { tools for human hazard } \\
\text { assessment }\end{array}$ & $\mathrm{P}$ & - & + & / & / & + & Low/high \\
\hline (P) NanoVALID (http://www.nanovalid.eu/) & $\begin{array}{l}\text { In vivo tools for human } \\
\text { and environmental } \\
\text { hazard assessment }\end{array}$ & $\mathrm{P}$ & - & + & l & / & + & Low \\
\hline $\begin{array}{l}\text { (P) NanoVALID (Oostingh et al., 2013, Kohl } \\
\text { et al., 2011) }\end{array}$ & $\begin{array}{l}\text { In vitro tools for human } \\
\text { hazard assessment }\end{array}$ & $\mathrm{P}$ & - & + & l & / & + & Low/high \\
\hline $\begin{array}{l}\text { (P) NANOMILE (Madani et al., 2012) } \\
\text { (http://nanomile.eu-vri.eu/) }\end{array}$ & $\begin{array}{l}\text { In vitro tools for human } \\
\text { hazard assessment }\end{array}$ & $\mathrm{P}$ & - & + & l & / & + & Low \\
\hline $\begin{array}{l}\text { (P) EURO-NanoTox (Mrakovcic et al., 2013, } \\
\text { Mrakovcic et al., 2014) }\end{array}$ & $\begin{array}{l}\text { In vitro tools for human } \\
\text { hazard assessment }\end{array}$ & $\mathrm{P}$ & - & + & l & / & + & Low/high \\
\hline $\begin{array}{l}\text { In Silico tools, incl. Quantitative } \\
\text { Nano-structure Activity Relationships } \\
\text { (QNAR) (Burello and Worth, 2011a, } \\
\text { Burello and Worth, 2011b, Puzyn et al., } \\
\text { 2011, Puzyn et al., 2009a, Puzyn et al., } \\
\text { 2009b, Toropov et al., 2007, Toropov and } \\
\text { Leszczynski, 2006, Liu et al., 2013b, Liu et } \\
\text { al., 2014, Liu et al., 2013a, Gómez et al., } \\
\text { 2013) }\end{array}$ & $\begin{array}{l}\text { In silico tools for hazard } \\
\text { assessment }\end{array}$ & M & - & + & - & - & + & low/high \\
\hline $\begin{array}{l}\text { (P) MODERN QNAR (Liu et al., 2014, Liu et } \\
\text { al., 2013a, Liu et al., 2013b) }\end{array}$ & $\begin{array}{l}\text { In silico tools for hazard } \\
\text { assessment }\end{array}$ & M & - & + & + & - & + & Low/high \\
\hline (P) NANOREG & $\begin{array}{l}\text { Physicochemical } \\
\text { characterization }\end{array}$ & $\mathrm{P}$ & - & + & / & / & + & Low/high \\
\hline (P) MARINA & $\begin{array}{l}\text { Physicochemical } \\
\text { characterization }\end{array}$ & $\mathrm{P}$ & - & \pm & / & / & - & Low \\
\hline $\begin{array}{l}\text { (P) NanoVALID } \\
\text { (http://www.nanovalid.eu/) }\end{array}$ & $\begin{array}{l}\text { Physicochemical } \\
\text { characterization }\end{array}$ & $\mathrm{P}$ & - & + & / & / & + & Low \\
\hline (P) NANOMILE (Madani et al., 2012) & $\begin{array}{l}\text { Physicochemical } \\
\text { characterization }\end{array}$ & $\mathrm{P}$ & - & + & / & / & + & Low/high \\
\hline (P) NANODEFINE & $\begin{array}{l}\text { Physicochemical } \\
\text { characterization }\end{array}$ & $\mathrm{P}$ & - & + & / & / & + & Low/high \\
\hline $\begin{array}{l}\text { (P) NANOLYSE } \\
\text { (http://www.nanolyse.eu/default.aspx) }\end{array}$ & $\begin{array}{l}\text { Physicochemical } \\
\text { characterization }\end{array}$ & $\mathrm{P}$ & - & + & / & / & + & Low/high \\
\hline $\begin{array}{l}\text { (P) NANOSAFER } 2 \\
\text { (http://nanosafer.i-bar.dk/) }\end{array}$ & RA model & M & - & \pm & \pm & - & - & Low/high \\
\hline (P) LICARA (Van Harmelen et al., 2016) & Decision support tool & M & + & \pm & - & + & - & Low \\
\hline (P) SUN DSS & Decision support tool & M & + & + & + & + & + & Low/high \\
\hline $\begin{array}{l}\text { (P) GUIDEnano DSS } \\
\text { (http://www.guidenano.eu/) }\end{array}$ & RA model & M & + & + & + & + & - & Low/high \\
\hline
\end{tabular}

parameters such as structural and chemical properties (e.g. particle size, density, composition, solubility, and aggregation), environmental fate indicators (e.g. partitioning coefficients, persistence), reactivity indicators (e.g. surface charge), application-specific data (e.g. numbers of products, exposed individuals), and use patterns to rank MNs in terms of human health risk. Similarly, Tervonen et al. (2009) developed a semi-quantitative tool for health and environmental risk classification of MNs based on Stochastic MultiCriteria Acceptability Analysis (SMAA-TRI). It is based on a set of performance criteria that measure the toxicity of the pristine materials, their physicochemical characteristics and expected environmental impacts (Tervonen and Figueira, 2008). Hristozov et al. (2014) developed the first quantitative Multi-Criteria Decision Analysis (MCDA) methodology for human health hazard identification of 
MNs, which incorporated data quality evaluation of the available dataset, based on the criteria adequacy, reliability, statistical and toxicological significance. Moreover, Hristozov et al. (2014) proposed a quantitative MCDA approach for prioritization of nano-specific exposure scenarios in occupational settings, and Hristozov et al. (2016) developed a quantitative MCDA methodology for human health risk ranking of MNs.

Some of these tools are capable of assessing uncertainties. The Precautionary Matrix for Synthetic Nanomaterials uses a "specific framework conditions" criterion that represents uncertainties resulting from knowledge gaps with respect to the origin of the MNs, their characteristics and uses. The tool by Tervonen et al. (2009) is able to conduct quantitative uncertainty analysis, while the models by Hristozov et al. $(2014,2016)$ perform probabilistic Monte Carlo sensitivity and uncertainty analyses. These stochastic analyses demonstrated that variations in the input parameters (i.e. exposure concentrations) did not significantly affect the obtained results. However, the considerable uncertainty in the input data called for the careful interpretation of the obtained results.

While they may be suggestive of innovative strategies for risk prioritization, the majority of the above risk screening tools have not been thoroughly tested yet and therefore their robustness has not been confirmed (Grieger et al., 2012). One exception is the approach by Tervonen et al. (2009), which was applied to fullerenes, cadmium-selenium quantum dots, silver ( $\mathrm{Ag}$ ) and aluminum ( $\mathrm{Al}) \mathrm{MNs}$, and multi-walled carbon nanotubes (CNTs). The input data was either derived from the literature or from expert judgement. In addition, the tools by Hristozov et al. $(2014,2016)$ were applied in real industrial case studies involving nanoscale Titanium dioxide $\left(\mathrm{TiO}_{2}\right)$, $\mathrm{Ag}$, Zinc oxide $(\mathrm{ZnO})$ and CNTs with data derived from the EU-funded projects ENPRA, NANEX and MARINA. The application of the above approaches demonstrated highest risks in exposure scenarios concerned with handling of large amounts of dry powders (e.g. bag/bin filling, manual un/loading, dumping). Scenarios, where the risks were relatively high involved handling of dry powders in smaller quantities (e.g. transferring of materials for solution preparation, weighing). In contrast, wet chemistry and laser ablation synthesis processes posed negligible risks due to very low emissions.

\subsubsection{Exposure assessment tools}

3.2.2.1. Occupational and consumer exposure tools. Several quantitative exposure models for chemicals were developed as a response to requirements under the European REACH regulation. These conservative easy-to-use Tier 1 tools include ECETOC TRA, MEASE, Stoffenmanager, ConsExpo, EMKG-EXPO-TOOL and RISKOFDERM. The majority of them estimate occupational inhalation exposure, while ECETOC TRA and CONSEXPO also address consumer inhalation and dermal exposure. The Advanced REACH Tool (ART) is a Tier 2 inhalation model, while the Dermal Advanced REACH Tool (DART) (Gorman et al., 2012) estimates dermal exposure. Unfortunately, none of these tools were calibrated for MNs, but for some of them this is currently work in progress. For instance DART is currently being tailored to MNs in the SUN project, which develops a tiered qualitative to quantitative framework and a tool to assess not only inhalation, but also dermal and dermal-to-oral occupational and consumer exposure to MNs.

In addition, a number of nano-specific qualitative or semi-quantitative tools were developed for consumer (Hansen et al., 2011), and occupational (Genaidy et al., 2009, Paik et al., 2008, Duuren-Stuurman et al., 2011, Giacobbe et al., 2009) exposure assessment. Some prominent examples are Stoffenmanager Nano (Duuren-Stuurman et al., 2011) and NanoSafer (Jensen et al., 2013), which consider personal exposure in their estimations, while NanoSafer bases its assessment on time-resolved exposure estimates and allows evaluation of both acute and chronic exposure. These approaches are currently being upgraded in the SUN project to incorporate important aerosol dynamic processes and uncertainty analysis functionalities. Aerosol dynamic modelling is a major step forward in the exposure assessment of MNs, but is constrained by the lack of well-characterised exposure scenarios, including sufficient data on source strengths, workplace measurements and contextual information.

Such scenarios have been developed in EU-funded research projects such as NANEX, MARINA, and SUN, and are compiled in data libraries. In order to progress from individual libraries to exposure data infrastructure the Partnership for European Research on Occupational Safety a Health (PEROSH) developed the Nano Exposure \& Contextual Information Database (NECID). NECID is intended to support its users to fulfill scientifically agreed requirements on information gathering for occupational exposure assessment of MNs, and to provide a general overview of MNs exposure measurements in different scenarios. Such a database is useful not only for exposure modelling, but also for read-across of information from one scenario to another, which can enable RA in datapoor situations.

3.2.2.2. Environmental fate and exposure tools. One major drawback in the ecological RA of MNs are the difficulties to detect them in natural environments due to lack of adequate tools to discriminate them from background nanoparticles. In order to enable environmental exposure assessment of MNs in the absence of reliable measurements, several environmental fate models were developed, which can be broadly categorized as "material flow" and "mechanistic" fate models.

3.2.2.3. Material flow models. The material flow analysis (MFA) models developed for MNs are based on the standard MFA methodology (Brunner and Rechberger, 2004) and the framework for CSA as outlined in the REACH guidance document (ECHA, 2010). The majority of these tools are quantitative and are not easy to apply by non-experts. In most of them releases into the environment are evaluated from lifecycle perspective and they use "transfer coefficients", derived from empirical data and informed assumptions about the transport of MNs between technical and environmental compartments, to estimate Predicted Environmental Concentrations (PECs) (Gottschalk et al., 2010b, Sun et al., 2014, Gottschalk et al., 2009, 2013, 2011).

Boxall et al. (2008) developed the first quantitative model to estimate PECs for MNs. It is a rather simple system of mathematical algorithms, which requires data on MNs production volumes and uses to estimate concentrations in water, soil, and air. Mueller and Nowack (2008) developed the approach further by assuming steady state conditions and homogeneous concentrations in the environmental compartments based on recommendations from the REACH guidance for CSA (Echa, 2010). In order to address some of the limitations of the above tools and strengthen their capacity to account for the high input data and modelling uncertainties, Gottschalk et al. (2010a) proposed a probabilistic model involving Monte Carlo, Bayesian and Markov Chain analyses. This model uses input parameters, such as nano-specific production and consumption volumes, fate pathways and transfer coefficients to derive probability distributions of possible PECs. Several other MFA-based seminal variations of the above models were published (Blaser et al., 2008, Wigger et al., 2015, Keller et al., 2013, O'brien and Cummins (2011)). Some significant limitations of these tools are that relevant compartments, such as groundwater and sediments, and certain essential processes, such as aggregation/agglomeration, sedimentation, re-suspension, degradation and transformation, were not considered in the estimations.

The approach byO'brien and Cummins (2011) represents one of the first attempts to combine MFA and colloidal chemistry. The U.S. Center for Environmental Implications of Nanotechnology (CEINT) developed a similar tool to estimate environmental concentrations of MNs in surface waters and sediments (DALE et al., 2015). Some processes considered by the CEINT model include runoff from crop soils, sewage treatment plant effluent loads to the stream, flow-dependent sediment transport (settling and re-suspension) and its impact on nanoparticle 
mobility in the stream and the sediment bed. It also considers nanoparticle transformations in the water column and the sediment as a function of spatiotemporal variation in oxygen, sulfide and temperature.

The majority of the reviewed MFA models have the ability to account in some ways for the large uncertainties in regards to the releases of MNs from products and/or industrial processes, production volumes, and use scenarios. Some of them considered ranges of best-case, realistic and worst-case scenarios in estimating exposure instead of generating highly uncertain, and therefore misleading PECs for single scenarios (Mueller and Nowack, 2008, Gottschalk et al., 2010b, 2011, Gottschalk, 2013). The more recent tools used probabilistic (e.g. Monte Carlo) methods to characterize the uncertainty and variability in the obtained results (Gottschalk et al., 2010a, O'brien and Cummins, 2011, Gottschalk et al., 2011, Gottschalk, 2013).

Most of the MFA models were demonstrated in case studies. The tool by Boxall et al. (2008) for example was applied to model the exposure of $\mathrm{C}_{60}$ fullerene and nanoscale $\mathrm{Ag}, \mathrm{Al}_{1} \mathrm{TiO}_{2}, \mathrm{ZnO}$, Latex and Hydroxyapatite in the UK. Similarly, the model by Mueller and Nowack (2008) was applied to calculate PECs for nanoscale $\mathrm{Ag}, \mathrm{TiO}_{2}$ and $\mathrm{CNT}$ released into air, soil and water in Switzerland. Both assessments were based on significant assumptions about market penetrations and consumer uses and lacked any analysis of the associated uncertainties. The tool by O'brien and Cummins (2011) was applied for estimating exposure to nanoscale $\mathrm{TiO}_{2}$, $\mathrm{Ag}$ and $\mathrm{CeO}_{2}$ released from paints, food packaging and fuel additives, but unlike the above studies this assessment involved uncertainty analysis. The Gottschalk et al. (2010a) model has been continuously updated in the MARINA and SUN projects and its new versions were used to calculate concentrations of nanoscale $\mathrm{TiO}_{2}, \mathrm{ZnO}, \mathrm{Ag}, \mathrm{CNT}$ and fullerenes in environmental and technical compartments by applying the newest data on MNs production volumes, release from products and material flows (Gottschalk et al., 2013, Sun et al., 2014). These analyses showed that the production volume and the compounds' inertness are crucial factors determining their final environmental concentrations. In the SUN project the model was upgraded to consider important end-of-life scenarios such as incineration and recycling (Caballero-Guzman et al., 2015, Walser and Gottschalk, 2014), where significant release of MNs is expected to occur. CEINT tested their model with nanoscale $\mathrm{ZnO}$ and Ag using the James River Basin in Virginia as a case study (DALE et al., 2015).

3.2.2.4. Dynamic models. There are a number of quantitative models, based on insights from colloidal chemistry, which account for the agglomeration/aggregation, sedimentation, re-suspension and dissolution dynamics of MNs (Ardvisson et al., 2011, Meesters et al., 2014, Money et al., 2012, Dale et al., 2013). The majority of these approaches cannot be characterised as user-friendly tools. One exception is the SimpleBox4Nano (Meesters et al., 2014), which is a screening-level fate model that considers the transport and concentrations of MNs in and across air, rain, surface waters, soil, and sediment, and accounts for nano-specific processes such as agglomeration/aggregation, attachment, and dissolution. The model is implemented as a user-friendly Microsoft Excel spreadsheet, supported by numerical computations in $\mathrm{R}$, which are linked to the spreadsheet via RExcel. It solves mass balance equations based on first-order rate constants by means of simple matrix algebra. The output of the model is mass concentrations of MNs as free dispersive species, heteroaggregates with natural colloids, and larger natural particles in each compartment as function of time and in steady state.

Similarly, the model by Ardvisson et al. (2011) provides the means to estimate particle number concentrations in the aquatic environments resulting from processes such as materials inflow, homo- and hetero agglomeration/aggregation and sedimentation, which are considered driving forces behind the transport of MNs in waters and their potential elimination from them. In order to achieve similar results, in addition to these phenomena, the model by Quik et al. (2014) takes into consideration also processes such as advection, volatilisation, chemical degradation, dissolution, and deposition, which makes it less strictly nano-specific and therefore applicable also to chemicals.

Money et al. (2012) adopted a different quantitative approach applying Bayesian networks in combination with expert elicitation as a tool for nanomaterial risk forecasting to develop a baseline probabilistic model that incorporates nano-specific characteristics and environmental parameters, along with elements of exposure potential, hazards, and risks from MNs. The Bayesian nature of FINE (Forecasting the Impacts of Nanomaterials in the Environment) allows for updating as new data become available.

CEINT, in collaboration with the Transatlantic Initiative for Nanotechnology and the Environment (TINE), developed a model to predict the distribution and speciation of both nanoscale and ionic Ag in freshwater sediments as a function of seasonally variable organic carbon, dissolved oxygen, sulfide, and temperature (Dale et al., 2013). The authors used concepts from colloidal chemistry to apply a conventional mass balance approach by adapting a model of cadmium speciation and distribution developed by Di Toro et al. (1996). The model was calibrated to data collected from Ag-dosed large-scale freshwater wetland mesocosms run by the CEINT. It was designed specifically for Ag, but the same principles could also be applied to other MNs (Dale et al., 2013).

The models by Ardvisson et al. (2011) and Quik et al. (2014) were discussed on a conceptual level only and were never applied in case studies. In contrast, the SimpleBox4Nano tool was demonstrated in scenarios for Switzerland, and evaluated the impact of transport processes on the final PECs. The CEINT/TINE tool was tested with nanoscale Ag data from freshwater wetland mesocosms. Similarly, the tool by Money et al. (2012) was applied to estimate nano Ag concentrations in aquatic environments (Money et al., 2012).

3.2.2.5. Behaviour and fate experiments. The above models need empirical data for validation. The environmental fate and behaviour of MNs are determined by several processes, which depend not only on the characteristics of the MNs but also on the media embedding them (Tiede et al., 2008). In aquatic systems, important processes affecting the transport, transformation and bioaccumulation of MNs include aggregation and disaggregation, dissolution, precipitation, diffusion, advection, sedimentation etc. (Ardvisson et al., 2011, Quik et al., 2014). MNs characteristics such as surface affinity are the driving forces for dissolution and biotransformation processes as well as for the complex interactions with abiotic and biological surfaces (Quik et al., 2014). It is important to understand how these characteristics can be linked to the nano-specific models described above as well as to certain partitioning and bioavailability models established for conventional chemicals. In order to achieve this more data and mechanistic knowledge need to be generated. One major reason for the current lack of such data is the deficiency of experimental protocols for characterization of MNs in (complex) environmental media, which has emerged from difficulties to distinguish the MNs from background particles of similar chemical composition. Several projects are currently developing tools to identify key characteristics of MNs that affect their fate based on combinations of MNs labeling and advanced measurement techniques such as X-ray absorption spectroscopy (XAS), Atomic force microscopy (AFM), Field flow fractionation (FFF), and Inductively coupled plasma mass spectrometry (ICP-MS).

One of these projects was the EU-funded MARINA, where researchers developed protocols to study the mobility of MNs in order to predict their exposure concentrations in different environmental compartments (i.e. soil, sediment and freshwater) with the idea to turn these procedures into standards. Some of these protocols are based on the OECD Test Guideline (TG) 312: Leaching in Soil Columns, and involve soil column chromatography in disturbed soil to determine the leaching potential of the test substance, and the leaching potential of transformation products in soils under controlled laboratory conditions. These protocols involve detailed physicochemical characterization of the MNs and the exposure media by means of advanced analytical 
methods such as ICP-MS and Scanning Electron Microscopy (SEM) (Kühnel and Nickel, 2014). Other methods aim to measure extremely low number concentrations of MNs in complex environmental matrices by single particle ICP-MS (Tuoriniemi et al., 2014, Cornelis and Hassellov, 2014).

Another key EU-funded project developing the understanding of the release, behaviour, fate and exposure to MNs is SUN. The SUN partners collect nanoscale fragments released from seven real industrial products at different lifecycle stages in order to characterize their physicochemical properties in biological (cell culture) and environmental (soil, sediment and water) media. The project studies the physicochemical transformations of MNs during release and in the environment in order to identify the properties of those MNs that reach environmental organisms or humans. SUN is also actively contributing to the work of the OECD on developing standard protocols for environmental fate in support to the RA of MNs. Specifically, the project is contributing to the implementation of the OECD TG 105 on water solubility for MNs.

3.2.2.6. Kinetic tools for estimation of human internal exposure. Computational physiologically-based pharmacokinetic (PBPK) models can incorporate toxicokinetic data along with species-specific physiological properties to study the post-exposure absorption, distribution, metabolism and excretion (ADME) of MNs (Lee et al., 2009, Riviere, 2009, Lankveld et al., 2010, Van Kesteren et al., 2014). Specific PBPK tools were proposed by Lee et al. (2009) for quantum dots, by Lankveld et al. (2010) for nano Ag, and by Van Kesteren et al. (2014) for nano $\mathrm{SiO}_{2}$. A generic PBPK model for MNs was developed by IOM in collaboration with the U.S. NIOSH agency in the context of the EU FP7 ENPRA and MARINA projects (Riviere, 2014). It is an adaptation and extension of an earlier PBPK model for larger particles, which was calibrated with data from the EU ENPRA, NANOMMUNE and NANOTEST projects. Such a model can be used to characterize the ADME profiles of the MNs for a diverse range of species based on particle type and physicochemical properties. Moreover, it can help to develop MN-specific uncertainty factors for interspecies differences in kinetics (e.g. between rodents and humans). PBPK modelling may facilitate extrapolation in exposure duration, e.g. tissue concentration levels for chronic exposure. However, as we do not fully understand the factors driving the MNs distribution between blood/plasma and tissues, extrapolations should be considered and interpreted with caution.

There is lack of reliable experimental data to validate nano-specific PBPK models. In order to fill this gap, several projects have developed and/or applied in vivo kinetic protocols. For instance, the U.S. STAR project developed methods to determine the distribution, persistence, translocation on and biotransformation of metal oxide MNs, their tolerability, and effects, focusing on oxidative stress endpoints (Yokel et al., 2009, Yokel et al., 2012, Hardas et al., 2010). This tool is an in vivo protocol including comprehensive physicochemical characterization for properties such as size, shape, zeta potential, extent of surface coating, and solubility. It includes investigation of multiple oxidative stress and inflammatory markers (Yokel et al., 2009, Yokel et al., 2012, Dan et al., 2011). Moreover, the EU-funded SUN project adapted and applied the Short-term Inhalation Studies (STIS) protocol developed in the NANOSAFE2 and NANOCARE projects (Klein et al., 2012). In addition, SUN developed a novel Short-term Oral Studies (STOS) protocol. Both STIS and STOS involve 5-day exposure with post-exposure examinations for up to 28 days and consider the assessment of progression or regression of effects and potential translocation to secondary organs, which are important aspects, currently not covered in the OECD TGs 412 and 413 (Klein et al., 2012). OECD TG 412 and 413 cover more endpoints and a longer exposure duration, and being OECD TG they fall under the legally binding "Mutual Acceptance of Data" principle that facilitates the international acceptance of information for the safety assessment of chemicals. Currently, the OECD TG programme reviews inhalation testing for MNs under the project: "Amendments to the
Inhalation Test Guidelines and Guidance to Accommodate Nanomaterials", which is led by U.S. EPA.

\subsubsection{Hazard assessment tools}

3.2.3.1. In vivo and in vitro toxicity testing tools. The OECD Testing Programme has evaluated the applicability of the TGs for conventional chemicals to MNs (OECD, 2009). Furthermore, it undertook to co-ordinate the testing of a set of MNs, and the outcomes of the experiments were published (OECD, 2016). Preliminary results have shown that most TGs are suitable for MNs but in some cases adaptations may be needed to address certain nano-specific characteristics. Therefore, the programme has started to work on adapting these TGs to MNs and to develop nano-specific TGs and guidance documents. In this context, in vivo and in vitro protocols for investigating the hazards of MNs have been developed and validated in a large number EU-funded projects (cf. Nanosafety Cluster Compendium). As a result a coherent hazard profile of MNs has emerged, demonstrating that reactive oxygen species, oxidative stress and modified inflammatory responses play important roles in their animal and cellular toxicity (Hristozov et al., 2014). The results of the above projects also show relationships between key physicochemical characteristics, modes of action and biological responses, indicating that factors such as surface area, reactivity, charge, solubility, shape and composition are all key.

A major gap in the field of human nanotoxicology is the lack of longterm inhalation and ingestion studies. In this context NANOREG performed a two-year inhalation study with $\mathrm{CeO}_{2}$, while SUN researchers transformed existing single and multi-species models to tools for estimating long-term and multi-generation environmental effects of MNs (Castro-Ferreira et al., 2014, Chen et al., 2014, Van Ommen Kloeke et al., 2014). Sewage Treatment Plants (STP) are among the first affected by released MNs (Yang et al., 2012), therefore SUN develops a tool to assess the possible impairment of STP biological function.

MARINA partners developed in vitro tools intended to determine the concentrations of MNs causing toxicity to cells and to establish basic mechanisms of toxicity such as alteration of e.g. cell membranes, metabolism and clearance mechanisms (Lammel et al., 2013). These tools aim to prioritize MNs for further testing and to determine realistic exposure concentrations to be applied in in vivo testing. In addition, according to the tools developers their outputs could be used directly for environmental RA in aquatic environment with conservative correction factors to account for in vitro-in vivo differences (Lammel and Navas, 2014).

NanoVALID researchers developed validated in vitro screening methods for MNs, which were included in decision trees to support optimal in vivo test design. The reproducibility of these tests across laboratories was checked by round-robins. Moreover, NanoVALID partners developed Enzyme-linked Immunosorbent Assay (ELISA) and Reverse Transcription Polymerase Chain Reaction (RT-PCR) assay responses of human lung cells exposed to any type of MNs via the gas phase (Oostingh et al., 2013, Kohl et al., 2011).

NanoMILE developed in vitro methods for high throughput screening of (eco)toxicity across a broad range of endpoints and species in order to identify mechanisms of toxicological action. In this context NanoMILE focused on developing tools for analysis of MNs interactions with environmental and biological macromolecules (e.g. proteins, lipids, sugars, nucleic acids) before and after uptake and localisation in cells. The project also developed tools to establish the nature and transformations of the MNs coronas under realistic environmental conditions (Madani et al., 2012).

EURO-NANOTOX researchers developed in vitro methods to investigate the kinetic behaviour (e.g. transport across barriers, tissue distribution, elimination) of various MNs (Mrakovcic et al., 2013, Mrakovcic et al., 2014). The project focussed on assessment of cellular particle uptake and evaluation of acute cellular effects. More specifically, the effects on specific organelles (lysosomes) are being studied. Particle uptake and cytotoxicity are assessed in physiologically relevant scenarios (e.g. co- 
culture systems, air-liquid interface cultures and microcarrier cultures). In order to perform these analyses, the project partners have developed cell cultures and various assays with microscopic and photometric/fluorometric/luminescent readout. These assays detect specific cellular changes due to the effects of MNs and provide results suitable to identify the underlying mechanisms of toxicological action (e.g. Ca-signalling, radical generation, decrease of lysosomal function).

3.2.3.2. In silico tools. The development of multiple similar, but not identical nanoforms by the nanotechnology industry poses an immediate problem for RA, as many of them remain untested for various reasons, one of which is the cost. To use the existing knowledge as efficiently as possible the development of Intelligent Testing Strategies for MNs was recommended (Stone et al., 2013). Such ITS would combine testing and non-testing methods to generate data for RA. In this context the development and application of in silico tools has become prominent and a number of such tools have been proposed (Burello and Worth, 2011a, Burello and Worth, 2011b, Puzyn et al., 2011, Puzyn et al., 2009a, KAR et al., 2014, Richarz et al., 2015, Toropova and Toropov, 2015, Labowsky et al.). Statistical analysis and machine learning methods (e.g. principal component analysis, neural networks) have also been applied to model the properties and effects of MNs (Puzyn et al., 2009b, Puzyn et al., 2009a, Toropov et al., 2007, Toropov and Leszczynski, 2006, Sayes et al., 2013, Lynch et al., 2014). Such methods were used for example in the EU-funded MODERN project with the aim to establish in silico modelling of the effects of metal and metal oxide MNs (Liu et al., 2013b, Liu et al., 2014, Liu et al., 2013a, Gómez et al., 2013).

\subsubsection{Risk assessment models}

Some high-tier quantitative models have been developed for both environmental and human health RA. These tools require a certain level of expertise to apply and are therefore not user-friendly from the point of view of non-experts. The only such tool capable of performing uncertainty analysis is the Species Sensitivity Distribution (SSD) approach proposed by Gottschalk et al. (2013), which uses a Monte Carlo probabilistic approach to generate SSD that are then compared with probability distributions of PECs for estimation of environmental risks. Semenzin et al. (2015) developed a Species Sensitivity Weighted Distribution (SSWD) methodology, which similarly estimates SSD. Its distinguishing feature is that it combines species relevance and trophic level abundance criteria to evaluate reliability of ecotoxicological data and their relevance for ecological RA (Semenzin et al., 2015).

NanoSafer 2 is a quantitative model that uses data on material properties, processes and production facilities to assess occupational risk. A key new development as compared to the former version of the tool is its capability to estimate exposure from spray processes. In addition, it can perform nano-specific hazard assessment based on read-across between MNs on the basis of material properties and hazard indicators. The results of this assessment can then be tested against in vivo experiments. The tool uses the Risk Quotient (i.e. the ratio of an exposure dose to a human effect threshold) to estimate risk.

The EU-funded GUIDENANO project is developing another quantitative web-based RA tool covering the hotspots of exposure and hazard important for human and environmental health during the entire life cycle of nano-enabled products. One of the distinguishing features of the tool includes the description of the MNs form in all its life cycle stages.

The NanoSafer 2 and GUIDEnano tools still have no documented applications, while the models by Gottschalk et al. (2013) and Semenzin et al. (2015) were tested in real case studies, including pristine $\mathrm{TiO}_{2}$ as well as $\mathrm{Ag}, \mathrm{Zn}, \mathrm{CNTs}$ and fullerenes released from consumer products in surface waters, sewage treatment plant effluents, soils and sludge-treated soils.

\subsubsection{Physicochemical characterization tools}

In order to identify if a pristine (as produced) substance is a nanomaterial one can use the European Commission's or sector-specific regulatory definitions (e.g. the ones for cosmetics or food), which are mainly based on size distribution and volume specific surface area. However, pristine MNs undergo transformation reactions during incorporation into products and when released from them. The released materials age under various environmental conditions. Thus, at each lifecycle stage there is a potential of exposure to MNs with different physicochemical properties (Hristozov et al., 2014, Oomen et al., 2014b, Arts et al., 2015b). A portfolio of physicochemical characterization techniques is required to understand the identity of the MNs reaching target organs and environmental species. It is essential that these tools are validated and reproducible across laboratories.

A number of efforts are currently underway both on the European and international levels to develop such tools for MNs. Some key initiatives are the EU-funded projects NANOVALID, MARINA, NANODEFINE, SUN, NANOLYSE, and NANOREG, which work in close collaboration to develop and test protocols for sample preparation and physicochemical characterization of both pristine MNs and such released from products into the environment.

NANOVALID developed validated protocols for measuring MNs and controlling their dispersion stability by means of novel labeling methods. The project developed new approaches to increase precision and reproducibility of tools for detection of low MNs concentrations in (complex) biological and environmental samples. This includes, among others, advanced secondary electron and optical imaging and spectroscopic techniques for analysis of chemical composition, size and morphology. Similarly, NanoDefine developed sampling strategies, dispersion and characterization protocols for MNs able to distinguish between large primary constituent particles and non-dispersible aggregates. The project identified and improved rapid screening methods such as Nanoparticle Tracking Analysis (NTA), Centrifugal Liquid Sedimentation (CLS), and ICP-MS.

The SUN project focused on developing methods for the characterization of MNs released from products and aged in the environment. Some examples are the following: i) single particle ICPMS with reaction cell technology for detection of nanoscale $\mathrm{Fe}_{2} \mathrm{O}_{3}$ and $\mathrm{CuO}$; ii) combination of AF4 and ICPMS for detection of nanoscale $\mathrm{SiO}_{2}$ in food; iii) protocols for release of $\mathrm{Fe}_{2} \mathrm{O}_{3}$ from plastics and $\mathrm{SiO}_{2}$ from food; iv) climate chamber weathering protocols for: a) $\mathrm{Fe}_{2} \mathrm{O}_{3}$ in plastics, and b) $\mathrm{CuO}$ painted on wood; v) wet weathering protocols for $\mathrm{Fe}_{2} \mathrm{O}_{3}$ and organic pigments in plastics; vi) a protocol for studying the release of MWCNT from polymers (based on isotopic labeling- $-{ }^{14} \mathrm{C}-\mathrm{CNTs}$ ); vii) protocols for studying the release of MNs from waste during incineration, recycling and landfilling.

NANOREG theoretically evaluated a number of OECD TG with a view to improve and validate them for MNs and also identified SOPs for water solubility and dispersion stability testing. The procedures include elemental analysis with ICP-MS and FFF and are applicable to in vitro cell culture and ecotoxicity dispersion media, where direct measurement by DLS may be hindered due to the presence of heterogeneous organic material (e.g. cells, exudates, proteins) in the medium.

In addition to developing methods for sample preparation and characterization of pristine and weathered MNs for (eco)toxicological evaluation and fate experiments, there is a pressing need for analytical methods that allow the routine detection of MNs in food. Researchers from the NANOLYSE project addressed this need by developing sample preparation methods, rapid imaging, screening and analytical protocols for the identification, characterization and quantification of inorganic and organic nanoparticles in the matrix of food products. These protocols are based on various techniques such as Electron microscopy, Surface Plasmon Resonance biosensor, Immunoassays (ELISA), Multidetector Field Flow Fractionation (FFF-UV/LS/ICP-MS), single particle ICPMS, Hydrodynamic Chromatography, and Differential Mobility Analysis. These methods were developed for food/beverage matrices, but can be 
extended to other complex matrices such as biological or environmental samples.

\subsubsection{Decision analytical tools}

Decision analytical methods (e.g. Bayesian inference, weight of evidence, MCDA) are useful for identifying, clearly representing, and formally assessing aspects of decision making in order to recommend courses of action (Clemen and Reilly, 2013). Some of these methods are used in Decision Support Systems (DSS), which refer to a wide range of computer-based tools consisting of databases, computational models and user-friendly interfaces.

Subramanian et al. (2015) reviewed the state of the art in the area of decision analytical tools applicable to assess trade-offs among MNs risks, costs, and benefits. One of these tools is the LICARA NanoScan, which determines and weighs benefits versus risks over the lifecycle of MNs-based products (Van Harmelen et al., 2016). This low-tier tool is specifically intended for SMEs to help them identify sources of potential risks from their products so that they can take timely preventive actions. It uses principles and assessment criteria from the Precautionary Matrix, NanoRiskCat and Stoffenmanager Nano, and integrates them with expert judgement through MCDA. LICARA NanoScan is available as an online tool and will be integrated as the lower tier of the DSS currently developed in the SUN project. The higher tier of the SUN DSS will include a risk control module performing quantitative occupational, consumer and environmental RA. If the risks are not acceptable the tool will propose suitable RMM. In addition, it will perform Socioeconomic Analysis (SEA) to check if the benefits of using certain nanoproducts significantly outweigh their risks.

\section{Discussion and conclusions}

In order to assess the strengths and limitations of the existing frameworks and tools for RA of MNs we adopted a multi-perspective methodology that combined a classical review of peer-reviewed papers with an analysis of grey literature and a survey to collect information from ongoing and completed nanoEHS research projects. We deem that this methodology was successful in collecting most information needed for our critical appraisal of the existing nanoEHS toolbox. Nevertheless, we encountered some issues, especially in conducting the survey, as the involved respondents often reported several tools in a single response, which made it difficult to evaluate them individually. This issue was particularly strong in the case of experimental protocols where the responders tended to report types of methods instead of single protocols. This phenomenon introduced ambiguity and likely errors in the assessment, which were impossible to avoid.

Based on our analysis, we conclude that none of the reviewed frameworks were able to fulfill all evaluation criteria. Therefore, we recommend the development of a comprehensive framework for RA of MNs that integrates all strengths listed in Table 3. Such a framework is needed for example to inform regulatory guidance. There has been a lot of discussion on possible adaptations of the REACH CSA for MNs and both industry and regulators need guidance on how to properly implement the CSA. The framework should represent an integrated (human health and environmental) strategy covering all stages of the lifecycles of nano-enabled products and should be able to address the needs of the different stakeholders (e.g. industries, regulatory agencies, insurance companies) involved in nanotechnology innovation supply chains. Moreover, the framework should be flexible enough to address different assessment goals depending on user needs, and should consider all data already available as starting point in order to select the most appropriate tools to fill the data gaps.

In generating data for hazard and exposure assessment the framework should take into consideration a number of nano-specific aspects, some of which recommended by OECD: i) sufficient data on the physicochemical properties of the MNs should be generated, including information on surface properties and interactions; ii) the effects of test methods and the exposure matrix on the testing outcomes and on inter-comparability of the data used in the assessment should be evaluated; iii) the complex nature of the material (e.g. variation in size, surface properties, and composition) that create a heterogeneous range of particle types should be considered, and iv) the interactions of the MNs in exposure and toxicity contexts should be taken into account.

The framework should selectively incorporate the existing tools for RA of MNs. There is an impressive number of such modelling tools and although they are intended to serve similar purposes (e.g. exposure, fate, hazard or risk assessment) their specifications (input data requirements, output formats, and application domains) vary considerably, which makes their integration in a consistent framework challenging. Most of the existing modelling tools are screening-level procedures to identify sources of human health risk in the lifecycle of MNs and to pinpoint areas of knowledge deficits. There is a pronounced need for quantitative tools that can effectively address the existing uncertainties in order to allow regulatory RA of MNs. Such tools have been developed in major projects, but most of them have not been calibrated and/or validated due to paucity of relevant experimental data. Therefore, several years may pass before they can be applied with confidence, while risk assessment results are needed in the near term to inform robust risk management decision making. The application of decision analytical methods (Subramanian et al., 2015) may be useful in addressing this need. Such tools can potentially overcome some of the limitations of the existing qualitative approaches, while at the same time contribute to a flexible framework for RA of MNs, adaptable to various needs. In addition, they can help the insurance sector develop risk transfer practices for nanotechnologies. This is indeed a pressing need as the current lack of practices (e.g. captives, self-insurance, risk sharing) to disperse risk through access to insurance markets may cause loss of investments in product development, which would affect the entire nanotechnology industry.

In order to facilitate regulatory RA of MNs in the medium-long term it is important to perform sensitivity testing analysis, performance testing, calibration and final demonstration of the different exposure, hazard, and risk modelling tools. Such sensitivity testing could use statistical methods to analyse the outputs from specific tools as function of their inputs. Tailored sensitivity and performance test paradigms should be established considering the types of tools and input data. The sensitivity analysis could involve screening analysis to rank the relative order of weight of each input, which can be followed by local and global sensitivity testing using the one-factor-at-a-time approach to assess the contribution of each input to the overall uncertainty in the assessment results.

In this way the sensitivity analysis can establish ranges of uncertainty as function of the different model inputs. This can facilitate the quantitative performance testing of the tools' predictability. The performance tests should be detailed enough to capture specific capabilities of the tools, such as the ability to perform exposure assessment of specific product groups. The outcome of the performance tests would be an analysis of the suitability, data availability, sensitivity, and observed uncertainty in the tests against the test data, as well as identification of further model development needs.

The results of the model analyses can inform experimental designs or monitoring practices to generate sufficient data for performance testing and validation. This iterative process would ideally lead to improving analytical/experimental protocols and tailoring them to the data needs of the modellers. It can be anticipated that these needs would cover physicochemical material or product characteristics, measured or estimated release or emission potentials, description of the exposure scenarios with contextual information, measured human exposure/environmental concentrations, test data from in vitro and in vivo (eco)toxicological studies.

Until now, the models discussed in this paper, at best, have only been demonstrated and not thoroughly tested and calibrated. Often, the model developers end up with the realization that existing data 
are not of sufficient quality and/or lack the necessary contextual information and conditions, which are required to truly calibrate and assess a models' performance. This has led to the generation of a considerable amount of empirical data on workplace and consumer exposure, including data on emission characteristics and source strengths from different release scenarios in the production and use stages, such as synthesis, powder handling, simulated sanding, drilling and cutting of nanocomposites, landfilling and incineration. Moreover, lots of data on physicochemical characteristics and (eco)toxicology of MNs have been generated. However, currently there are few reliable data for calibration and validation of the existing fate, transport and exposure models. One important reason for this is that the available sampling and measurement tools need further improvements before they could confidently distinguish MNs from background particles, which calls for more research on increasing their sensitivity and selectivity. Moreover, data are lacking on key processes determining the environmental fate and behaviour of MNs (e.g. aggregation, agglomeration, dissolution, resuspension), which have only recently been considered in the nano-specific environmental fate and exposure models. These processes depend not only on the characteristics of the MNs but also on the media embedding them, which complicates their monitoring. In aquatic systems, important processes affecting the transport, transformation and bioaccumulation of MNs include aggregation and disaggregation, dissolution, precipitation, diffusion, advection, and sedimentation. MNs characteristics such as surface affinity are the driving forces for dissolution and biotransformation processes as well as for the complex interactions with abiotic and biological surfaces. It is important to understand how these characteristics can be linked to the nano-specific models described above as well as to certain partitioning and bioavailability models established for conventional chemicals. To achieve this more data and mechanistic knowledge need to be generated. In order to generate these data, it is important to develop experimental techniques for investigating the agglomeration/aggregation kinetics of MNs in the aquatic, soil and sediment compartments with the specific goal of providing attachment efficiency factors for quantifying the association of MNs with suspended ambient solids and the removal of MNs from the water column to the sediment. This should involve the design of dedicated experimental protocols to define agglomeration/aggregation kinetics of selected MNs that are key in interpreting environmental fate and transport in realistic environments. Special attention should be given to experimental designs able to study how the MNs surface coating/functionalization influence their aggregation/agglomeration and sedimentation kinetics. These activities should be designed considering both MNs physicochemical properties (e.g. surface coating/ functionalization, dimension, surface charge, shape) and environmental parameters (e.g. temperature, salinity, organic carbon content), and should be directed especially towards addressing hetero-agglomeration/aggregation and sedimentation processes.

Moreover, future research should investigate dissolution kinetics as some MNs could dissolve rapidly into ions. This should involve dynamic testing approaches determining dissolution in a system where it happens towards an infinite sink, so that the rate is not changed due to back-reactions, which could occur in static systems, where dissolved ions build up in the medium during the dissolution process. This would better reflect the behaviour of MNs in the soil, where in a static test most of the produced ions would be quickly adsorbed to soil components, which would reduce the ion activity in the pore waters, and would accelerate the dissolution.

There have been considerable efforts to develop validated physicochemical characterization, environmental measurement, in vitro and in vivo testing protocols and to ensure that they generate data reproducible across laboratories. Nevertheless, the majority of these data and tools are currently scattered across project documentation and are difficult or impossible to access. Moreover, most of the data are recorded as large volumes of unstructured text (e.g. technical reports, journal articles), which makes it difficult to automate the process of information extraction and analysis. The data sources are also physically separate, forcing researchers to spend considerable time locating them. The existing database services use different interfaces, data formats and terminologies. These issues have created the pressing need to advance the current efforts on developing databases and tools towards developing an infrastructure to support a network of data and analytical services for nanoEHS research that share standard formats and a common ontology. This infrastructure should be open and accessible so that the available resources can be used freely for RA.

Using this infrastructure to access large sets of comparable physicochemical, hazard, release and exposure data could boost the development of computational in silico models and could facilitate in vitro-in vivo extrapolations. Such developments could eventually enable risk assessors to use the huge volume of existing in vitro data for RA of MNs, which would significantly reduce testing costs and the use of experimental animals. The analysis of these data by means of relevant statistical and machine learning techniques could help to develop strategies for grouping of MNs based on certain physicochemical, release, exposure, biokinetic and/or biological/toxicological attributes. Grouping can facilitate the risk assessment process through waiving of testing, or to highlight issues that need additional analysis. It could enable read-across among nanoforms and non-nanoforms, and could inform safer product design.

Grouping and read-across approaches are well-established for chemical substances, but a number of challenges prevent their successful implementation for MNs, including: i) the fact that many physicochemical and structural properties of pristine NMs are inter-related and thus cannot be analysed in isolation from others (e.g. increasing surface charge may impact on hydrophobicity, or changing the shape of a NM may introduce defects or alter the atomic configuration of the surface); ii) the ageing, transformation and coating of NMs by biomolecules in environmental or biological media may affect their interactions with organisms and cells, and thus modify their toxicity. Overcoming these challenges requires a profound understanding of which (combinations of) the intrinsic and extrinsic structural and physicochemical characteristics of MNs dispersed in environmental or biological media or embedded in product matrices affect their release potential, uptake, biokinetic behaviour, toxicological modes of action or adverse outcome pathways. In order to develop such understanding it is useful to generate data on the intrinsic and extrinsic properties derived from existing physicochemical analyses of pristine, released, aged and modified MNs in different biological and environmental media as well as the observed adverse effects based on (eco)toxicological studies.

There are differences in the perspectives of the existing grouping frameworks in terms of the hierarchy of relevant properties, but those are not contradictions. Instead they call for an integration in a consistent, multi-perspective strategy in order to i) help industries and regulators assess the environmental and human health risks of MNs in cost effective manner, and to ii) inform safer by design practices in the early stages of product development. In order to achieve the first, the framework should guide the user through the selection of established experimental and modelling approaches to generate the data needed for the identification and classification of NM according to regulatory definitions, and to enable predictive in silico modelling. In order to achieve the latter, the framework could be based on the StageGate concept so that the results of its application are fed directly into innovation supply chains. In order to increase the attractiveness of the framework for SMEs and industries, it would be useful to develop it into a userfriendly web-based decision support tool.

\section{Acknowledgments}

The work reported in this paper was funded by the European 7th Framework Programme MARINA project (grant number 263215). Special thanks to Vrishali Subramanian from University Ca' Foscari Venice for her technical support in conducting the online survey to identify 
tools for RA of MNs and to Kirsten Rasmussen from the European Commission's Joint Research Centre for her review of the paper, which significantly contributed to its improvement.

\section{Appendix A. Supplementary data}

Supplementary data to this article can be found online at http://dx. doi.org/10.1016/j.envint.2016.07.016.

\section{References}

Ardvisson, R., Molander, S., Sandèn, B.A., Hassellov, M., 2011. Challenges in exposure modeling of nanoparticles in aquatic environments. Hum. Ecol. Risk. Assess. 17, 245-262.

Arts, J., Hadi, M., Irfan, M.-A., Keene, A.M., Kreiling, R., Lyon, D., Maier, M., Michel, K., Petry T., Sauer, U.G., Warheit, D., Wiench, K., Wohlleben, W., Landsiedel, R., 2015a. A decision-making framework for the grouping and testing of nanomaterials (DF4nanoGrouping). Regul. Toxicol. Pharmacol. 71, S1-27.

Arts, J.H.E., Hadi, M., Irfan, M.-A., Keene, A.M., Kreiling, R., Lyon, D., Maier, M., Michel, K. Petry, T., Sauer, U.G., Warheit, D., Wiench, K., Wohlleben, W., Landsiedel, R., 2015b. A decision-making framework for the grouping and testing 2 of nanomaterials (DF4nanoGrouping). Regul. Toxicol. Pharmacol. 71, S1-S27.

Blaser, S.A., Scheringer, M., Macleod, M., Hungerbühler, K., 2008. Estimation of cumulative aquatic exposure and risk due to silver: contribution of nano-functionalized plastics and textiles. Sci. Total Environ. 390, 396-409.

Bos, M.P., Gottardo, S., Scott-Fordsmand, J.J., Van Tongeren, M., Semenzin, E., Fernandes, F.T., Hristozov, D., Hund-Rinke, K., Hunt, N., Irfan, M.-A., Landsiedel, R., Peijnenburg J.W., Sánchez Jiménez, A., Van Kesteren, C.P., OOMEN, G.A., 2015. The MARINA risk assessment strategy: a flexible strategy for efficient information collection and risk assessment of nanomaterials. Int. J. Environ. Res. Public Health 12.

Boxall, A., Chaudhry, Q., Jones, A., Jefferson, B., Watts, C., 2008. Current and future predicted environmental exposure to engineered nanoparticles. Sand Hutton, UK, Centra Science Laboratory York for the Department of the Environment and Rural Affairs.

Brouwer, D.H., 2012. Control banding approaches for nanomaterials. Ann. Occup. Hyg. 56 (5), 506-514.

Brunner, P.H., Rechberger, H., 2004. Practical Handbook of Material Flow Analysis. CRC Press, Boca Raton.

Burello, E., Worth, A., 2011a. QSAR modeling of nanomaterials. Wiley Interdiscip. Rev. Nanomed. Nanobiotechnol. 3, 298-306.

Burello, E., Worth, A.P., 2011b. A theoretical framework for predicting the oxidative stress potential of oxide nanoparticles. Nanotoxicology 5, 228-235.

Caballero-Guzman, A., Sun, T., Nowack, B., 2015. Flows of engineered nanomaterials through the recycling process in Switzerland. Waste Manag. 36, 33-43.

Castro-Ferreira, M., De Boer, T., Colbourne, J., Vooijs, R., Van Gestel, C., Van Straalen, N. Soares, A., Amorim, M., Roelofs, D., 2014. Transcriptome assembly and microarray construction for Enchytraeus crypticus, a model oligochaete to assess stress response mechanisms derived from soil conditions. BMC Genomics 15, 302.

Chen, G., De Boer, T.E., Wagelmans, M., Van Gestel, C.A.M., Van Straalen, N.M., Roelofs, D. 2014. Integrating transcriptomics into triad-based soil-quality assessment. Environ. Toxicol. Chem. 33, 900-909.

Clemen, R., Reilly, T., 2013. Making Hard Decisions with Decision Tools. Cengage Learning, Boston.

Cornelis, G., Hassellov, M., 2014. A signal deconvolution method to discriminate smaller nanoparticles in single particle ICP-MS. J. Anal. At. Spectrom. 29, 134-144.

Dale, A.L., Lowry, G.V., Casman, E.A., 2013. Modeling nanosilver transformations in freshwater sediments. Environ. Sci. Technol. 47, 12920-12928.

Dale, A.L., Lowry, G.V., Casman, E.A., 2015. Stream dynamics and chemical transformations control the environmental fate of silver and zinc oxide nanoparticles in a watershedscale model. Environ. Sci. Technol. 49, 7285-7293.

Dan, M., Wu, P., Grulke, E.A., Graham, U.M., Unrine, J.M., Yokel, R.A., 2011. Ceriaengineered nanomaterial distribution in, and clearance from, blood: size matters. Nanomedicine 7, 95-110.

Di Toro, D.M., Mahoney, J.D., Hansen, D.J., Berry, W.J., 1996. A model of the oxidation of iron and cadmium sulfide in sediments. Environ. Toxicol. Chem. 15 (12), 2168-2186.

Donaldson, K., Poland, C.A., 2013. Nanotoxicity: challenging the myth of nano-specific toxicity. Curr. Opin. Biotechnol. 24, 724-734.

Duuren-Stuurman, B., Vink, S., Brouwer, D., Kroese, D., Heussen, H., Verbist, K., Telemans, E., Niftrik, M.V., Fransman, W., 2011. Stoffenmanager Nano: description of the conceptual control banding model. Zeist, Netherlands: Netherlands Organisation for Applied Scientific Research (TNO).

ECHA, 2010. Guidance on Information Requirements and Chemical Safety Assessment Chapter r.16: Environmental Exposure Estimation. Helsinki, European Chemicals Agency.

ECHA, 2012a. Guidance on information requirements and chemical safety assessment. Appendix R 14.4 Recommendations for nanomaterials applicable to Chapter R.14 Occupational exposure estimation. Helsinki, European Chemicals Agency.

ECHA, 2012b. Guidance on information requirements and chemical safety assessment. Appendix R. 7.1 Recommendations for nanomaterials applicable to Chapter R.7 b Endpoint specific guidance. Helsinki, European Chemicals Agency.

ECHA, 2012c. Guidance on information requirements and chemical safety assessment Appendix R. 7.1 Recommendations for nanomaterials applicable to Chapter R. 7a Endpoint specific guidance. Helsinki, European Chemicals Agency.
ECHA, 2012d. Guidance on information requirements and chemical safety assessment. Appendix R. 7.2 Recommendations for nanomaterials applicable to Chapter R. 7 c Endpoint specific guidance. Helsinki, European Chemicals Agency.

ECHA, 2012e. Guidance on information requirements and chemical safety assessment Appendix R. 8.15 Recommendations for nanomaterials applicable to Chapter R.8 Characterisation of dose [concentration] - response for human health. Helsinki, European Chemicals Agency.

ECHA, 2012f. Guidance on information requirements and chemical safety assessment. Appendix R. 10.2 Recommendations for nanomaterials applicable to Chapter R.10 Characterisation of dose [concentration] - response for environment. Helsinki, European Chemicals Agency.

ECHA, JRC \& RIVM, 2016. Usage of (Eco)Toxicological Data for Bridging Data Gaps between and Grouping of Nanoforms of the Same Substance.

EFSA, 2010. Opinion on the Potential Risks Arising from Nanoscience and Nanotechnologies on Food and Feed Safety. European Food Safety Authority, Brussels.

Environmental Defense \& Dupont, 2007. Nano Risk Framework. Washington.

European Commission, 2010. Europe 2020 Flagship Initiative Innovation Union. Communication from the Commission to the European Parliament, the Council, the European Economic and Social Committee and the Committee of the Regions. Brussels.

Fransman, W., Cherrie, J., Tongeren, M.V., Schneider, T., Tischer, M., Schinkel, J., Marquart, H., Warren, N., Kromhout, H., Tielemans, E., 2009. Development of a mechanistic model for the Advanced REACH Tool (ART). Netherlands Organisation for Applied Scientific Research (TNO), Zeist, Netherlands.

Gebel, T., Foth, H., Damm, G., Freyberger, A., Kramer, P.-J., Lilienblum, W., Röhl, C., Schupp, T., Weiss, C., Wollin, K.-M., Hengstler, J.G., 2014. Manufactured nanomaterials: categorization and approaches to hazard assessment. Arch. Toxicol. 88, 2191-2211.

Genaidy, A., Sequeira, R., Rinder, M., A-Rehim, A., 2009. Risk analysis and protection measures in a carbon nanofiber manufacturing enterprise: an exploratory investigation. Sci. Total Environ. 407, 5825-5838.

Giacobbe, F., Monica, L., Geraci, D., 2009. Risk assessment model of occupational exposure to nanomaterials. Hum. Exp. Toxicol. 28, 401-406.

Gómez, S., Fernández, A., Granell, C., Arenas, A., 2013. Structural patterns in complex systems using multidendrograms. Entropy 15, 5464-5474.

Gorman, M., Poot, S.D., Schmid, K., Lamb, J., Cowie, H., Tongeren, M.V., 2012. Investigation of Determinants of Dermal Exposure to Enable Development of a Dermal Advanced REACH Tool (DART). Institute of Occupational Medicine, Edinburgh.

Gottschalk, F.A.N.B., 2013. A probabilistic method for species sensitivity distributions taking into account the inherent uncertainty and variability of effects to estimate environmental risk. Integr. Environ. Assess. Manag. 9, 79-86.

Gottschalk, F., Sonderer, T., Scholz, R.W., Nowack, B., 2009. Modeled environmental concentrations of engineered nanomaterials ( $\mathrm{TiO} 2, \mathrm{ZnO}, \mathrm{Ag}$, CNT, fullerenes) for different regions. Environ. Sci. Technol. 43, 9216-9222.

Gottschalk, F., Scholz, R.W., Nowack, B., 2010a. Probabilistic material flow modeling for assessing the environmental exposure to compounds: methodology and an application to engineered nano-TiO2 particles. Environ. Model Softw. 25, 320-332.

Gottschalk, F., Sonderer, T., Scholz, R.W., Nowack, B., 2010b. Possibilities and limitations of modeling environmental exposure to engineered nanomaterials by probabilistic material flow analysis. Environ. Toxicol. Chem. 29, 1036-1048.

Gottschalk, F., Ort, C., Scholz, R.W., Nowack, B., 2011. Engineered nanomaterials in rivers exposure scenarios for Switzerland at high spatial and temporal resolution. Environ. Pollut. 159, 3439-3445.

Gottschalk, F., Kost, E., Nowack, B., 2013. Engineered nanomaterials in water and soils: a risk quantification based on probabilistic exposure and effect modeling. Environ. Toxicol. Chem. 32, 1278-1287.

Grieger, K.D., Linkov, I., Hansen, S.F., Baun, A., 2012. Environmental risk analysis for nanomaterials: review and evaluation of frameworks. Nanotoxicology 6, 196-212.

Grieger, K., Redmon, J., Money, E., Widder, M., Van Der Schalie, W., Beaulieu, S., Womack, D., 2015. A relative ranking approach for nano-enabled applications to improve riskbased decision making: a case study of Army materiel. Environ. Syst. Decis. 35, 42-53.

Hansen, S.F., Baun, A., Alstrup-Jensen, K., 2011. NanoRiskCat-A Conceptual Decision Support Tool for Nanomaterials. Denmark Technical University, Kongens Lyngby.

Hansen, S., Jensen, K., Baun, A., 2013. NanoRiskCat: a conceptual tool for categorization and communication of exposure potentials and hazards of nanomaterials in consumer products. J. Nanopart. Res. 16, 1-25.

Hardas, S.S., Butterfield, D.A., Sultana, R., Tseng, M.T., Dan, M., Florence, R.L., Unrine, J.M., Graham, U.M., Wu, P., Grulke, E.A., Yokel, R.A., 2010. Brain distribution and toxicological evaluation of a systemically delivered engineered nanoscale ceria. Toxicol. Sci. 116, 562-576.

Höck, J., Epprecht, T., Hofmann, H., Höhner, K., Krug, H., Lorenz, C., Limbach, L., Gehr, P., Nowack, B., Riediker, M., Schirmer, K., Schmid, B., Som, C., Stark, W., Studer, C., Ulrich, A., Götz, N.V., Wengert, S., Wick, P., 2010. Guidelines on the Precautionary Matrix for Synthetic Nanomaterials. Federal Office of Public Health and Federal Office for the Environment, Berne.

Hristozov, D.R., Gottardo, S., Critto, A., Marcomini, A., 2012. Risk assessment of engineered nanomaterials: a review of available data and approaches from a regulatory perspective. Nanotoxicology 6, 880-898.

Hristozov, D., Maccalman, L., Jensen, K.A., Stone, V., Scott-Fordsmand, J., Nowack, B., Fernandes, T., Marcomini, A., 2014. Risk assessment of engineered nanomaterials: state of the art and roadmap for future research. In: Monteiro-Riviere, N.A., Tran, L (Eds.), Nanotoxicology: Progress Towards Nanomedicine. Informa Healthcare.

Hristozov, D., Zabeo, A., Jensen, K.A., Gottardo, S., Isigonis, P., Maccalman, L., Critto, A., Marcomini, A., 2016. Demonstration of a modelling-based multi-criteria decision analysis procedure for prioritization of occupational risks from manufactured nanomaterials. Nanotoxicology, http://dx.doi.org/10.3109/17435390.2016.1144827.

Jensen, K., Saber, A., Kristensen, H., Koponen, I., Liguori, B., Wallin, H., 2013. NanoSafer Vs. 1.1-Nanomaterial Risk Assessment Using First Order Modeling. 6th International 
Symposium on Nanotechnology, Occupational and Environmental Health, p. 120 (Nagoya, Japan).

Kar, S., Gajewicz, A., Puzyn, T., Roy, K., 2014. Nano-quantitative structure-activity relationship modeling using easily computable and interpretable descriptors for uptake of magnetofluorescent engineered nanoparticles in pancreatic cancer cells. Toxicol. in Vitro 28, 600-606.

Keller, A.A., Mcferran, S., Lazareva, A., Suh, S., 2013. Global life cycle releases of engineered nanomaterials. J. Nanopart. Res. 15.

Klein, C., Wiench, K., Wiemann, M., Ma-Hock, L., Ravenzwaay, B., Landsiedel, R., 2012. Hazard identification of inhaled nanomaterials: making use of short-term inhalation studies. Arch. Toxicol. 86, 1137-1151.

Kohl, Y., Oostingh, G., Sossalla, A., Duschl, A., Von Briesen, H., Thielecke, H., 2011. Biocompatible micro-sized cell culture chamber for the detection of nanoparticle-induced IL8 promoter activity on a small cell population. Nanoscale Res. Lett. 6, 505.

Kühnel, D., Nickel, C., 2014. The OECD expert meeting on ecotoxicology and environmental fate-towards the development of improved OECD guidelines for the testing of nanomaterials. Sci. Total Environ. 472, 347-353.

Lammel, T., Navas, J.M., 2014. Graphene nanoplatelets spontaneously translocate into the cytosol and physically interact with cellular organelles in the fish cell line PLHC-1. Aquat. Toxicol. 150, 55-65.

Lammel, T., Boisseaux, P., Fernandez-Cruz, M.-L., Navas, J., 2013. Internalization and cytotoxicity of graphene oxide and carboxyl graphene nanoplatelets in the human hepatocellular carcinoma cell line Hep G2. Part. Fibre Toxicol. 10, 27.

Lankveld, D.P.K., Oomen, A.G., Krystek, P., Neigh, A., Troost- De Jong, A., Noorlander, C.W., Van Eijkeren, J.C.H., Geertsma, R.E., De Jong, W.H., 2010. The kinetics of the tissue distribution of silver nanoparticles of different sizes. Biomaterials 31, 8350-8361.

Lee, H.A., Leavens, T.L., Mason, S.E., Monteiro-Riviere, N.A., Riviere, J.E., 2009. Comparison of quantum dot biodistribution with a blood-flow-limited physiologically based pharmacokinetic model. Nano Lett. 9, 794-799.

Liu, R., Hassan, T., Rallo, R., Cohen, Y., 2013a. HDAT: web-based high-throughput screening data analysis tools. Comput. Sci. Discovery 6, 014006.

Liu, R., Zhang, H.Y., Ji, Z.X., Rallo, R., Xia, T., Chang, C.H., Nel, A., Cohen, Y., 2013b. Development of structure-activity relationship for metal oxide nanoparticles. Nanoscale 5 , 5644-5653.

Liu, R., France, B., George, S., Rallo, R., Zhang, H., Xia, T., Nel, A.E., Bradley, K., Cohen, Y. 2014. Association rule mining of cellular responses induced by metal and metal oxide nanoparticles. Analyst 139, 943-953.

Lynch, I., Weiss, C., Valsami-Jones, E., 2014. A strategy for grouping of nanomaterials based on key physico-chemical descriptors as a basis for safer-by-design NMs. Nano Today 9, 266-270.

Madani, S., Tan, A., Dwek, M., Seifalian, A., 2012. Functionalization of single-walled carbon nanotubes and their binding to cancer cells. Int. J. Nanomedicine 7, 905-914.

Maynard, A.D., 2007. Nanotechnology: the next big thing, or much ado about nothing? Ann. Occup. Hyg. 51, 1-12.

Meesters, J.A.J., Koelmans, A.A., Quik, J.T.K., Hendriks, A.J., Van De Meent, D., 2014. Multimedia modeling of engineered nanoparticles with SimpleBox4nano: model definition and evaluation. Environ. Sci. Technol. 48, 5726-5736.

Money, E.S., Reckhow, K.H., Wiesner, M.R., 2012. The use of Bayesian networks for nanoparticle risk forecasting: model formulation and baseline evaluation. Sci. Total Environ. 426, 436-445.

Mrakovcic, M., Absenger, M., Riedl, R., Smole, C., Roblegg, E., Fröhlich, L.F., Fröhlich, E., 2013. Assessment of long-term effects of nanoparticles in a microcarrier cell culture system. PLoS One 8, e56791.

Mrakovcic, M., Meindl, C., Roblegg, E., Frohlich, E., 2014. Reaction of monocytes to polystyrene and silica nanoparticles in short-term and long-term exposures. Toxicol. Res. 3, 86-97.

Mueller, N.C., Nowack, B., 2008. Exposure modeling of engineered nanoparticles in the environment. Environ. Sci. Technol. 42, 4447-4453.

O'brien, N.J., Cummins, E.J., 2011. A risk assessment framework for assessing metallic nanomaterials of environmental concern: aquatic exposure and behavior. Risk Anal. 31, 706-726.

OECD, 2009. Preliminary Review of OECD Test Guidelines for their Applicability to Manufactured Nanomaterials.

OECD, 2010. Guidance Manual for the Testing of Manufactured Nanomaterials: OECD Sponsorship Programme-First Revision. Paris.

OECD, 2016. Testing Programme of Manufactured Nanomaterials-Dossiers and Endpoints [Online] ([Accessed])

OECD and European Commission, 2012. Series on the Safety of Manufactured Nanomaterials No. 33: Important Issues on Risk Assessment of Manufactured Nanomaterials. Paris.

Olson, M., Gurian, P., 2012. Risk assessment strategies as nanomaterials transition into commercial applications. J. Nanopart. Res. 14, 1-7.

Oomen, A.G., Bos, P.M.J., Fernandes, T.F., Hund-Rinke, K., Boraschi, D., Byrne, H.J., Aschberger, K., Gottardo, S., Von Der Kammer, F., Kuehnel, D., Hristozov, D., Marcomini, A., Migliore, L., Scott-Fordsmand, J., Wick, P., Landsiedel, R., 2014a. Concern-driven integrated approaches to nanomaterial testing and assessment - report of the NanoSafety Cluster Working Group 10. Nanotoxicology 8, 334-348.

Oomen, A.G., Bos, P.M.J., Fernandes, T.F., Hund-Rinke, K., Boraschi, D., Byrne, H.J., Aschberger, K., Gottardo, S., Von Der Kammer, F., Kühnel, D., Hristozov, D., Marcomini, A., Migliore, L., Scott-Fordsmand, J., Wick, P., Landsiedel, R., 2014b. Concern-driven integrated approaches to nanomaterial testing and assessment-report of the NanoSafety cluster working group 10. Nanotoxicology 8, 334-348.

Oomen, G.A., Bleeker, A.E., Bos, M.P., Van Broekhuizen, F., Gottardo, S., Groenewold, M., Hristozov, D., Hund-Rinke, K., Irfan, M.-A., Marcomini, A., Peijnenburg, J.W., Rasmussen, K., Jiménez, S.A., Scott-Fordsmand, J.J., Van Tongeren, M., Wiench, K., Wohlleben, W., Landsiedel, R., 2015. Grouping and read-across approaches for risk assessment of nanomaterials. Int. J. Environ. Res. Public Health 12.
Oostingh, G., Papaioannou, E., Chasapidis, L., Theofylaktos, A., Konstandopoulos, A. Duschl, A., 2013. On-line exposure system to determine immunotoxic effects of freshly produced diesel exhaust on human alveolar epithelial cells. Toxicol. in Vitro 27, 1746-1752.

Ostiguy, C., Riediker, M., Triolet, J., Troisfontaines, P., Vernez, D., 2010. Development of a Specific Control Banding Tool for Nanomaterials. French Agency for Food, Environmental and Occupational Health \& Safety, Maisons-Alfort Cedex.

Paik, S.Y., Zalk, D.M., Swuste, P., 2008. Application of a pilot control banding tool for risk level assessment and control of nanoparticle exposures. Ann. Occup. Hyg. 52, 419-428.

Pronk, M.E.J., Wijnhoven, S.W.P., Bleeker, E.A.J., Heugens, E.H.W., Peijnenburg, W.J.G.M., Luttik, R., Hakkert, B.C., 2009. Nanomaterials under REACH-Nanosilver as a Case Study. RIVM, Bilthoven, the Netherlands.

Puzyn, T., Leszczynska, D., Leszczynski, J., 2009a. Toward the development of "NanoQSARs": advances and challenges. Small 5, 2494-2509.

Puzyn, T., Mostrąg, A., Falandysz, J., Kholod, Y., Leszczynski, J., 2009b. Predicting water solubility of congeners: chloronaphthalenes-a case study. J. Hazard. Mater. 170, 1014-1022.

Puzyn, T., Rasulev, B., Gajewicz, A., Hu, X., Dasari, T., Michalkova, A., Hwang, H., Toropov, A., Leszczynska, D., Leszczynski, J., 2011. Using nano-QSAR to predict the cytotoxicity of metal oxide nanoparticles. Nat. Nanotechnol. 6, 175-178.

Quik, J.T.K., Velzeboer, I., Wouterse, M., Koelmans, A., D., V.D.M, 2014. Heteroaggregation and sedimentation rates for nanomaterials in natural waters. Water Res. 48, 269-279.

Renn, O., Roco, M., 2006. White Paper no. 2: Nanotechnology Risk Governance. International Risk Governance Council, Geneva.

Richarz, A.-N., Madden, J.C., Marchese Robinson, R.L., Lubiński, Ł., Mokshina, E., Urbaszek, P., Kuz'min, V.E., Puzyn, T., Cronin, M.T.D., 2015. Development of computational models for the prediction of the toxicity of nanomaterials. Perspect. Sci. 3, 27-29.

Riviere, J.E., 2009. Pharmacokinetics of Nanomaterials: An Overview of Carbon Nanotubes, Fullerenes and Quantum Dots. Wiley Interdisciplinary Reviews: Nanomedicine and Nanobiotechnology 1, pp. 26-34.

Riviere, J.E., 2014. Pharmacokinetics and Biodistribution of Nanomaterials. Nanotoxicology. CRC Press, Boca Raton.

RIVM, 2015. Grouping nanomaterials. A Strategy towards Grouping and Read-across.

Sayes, C.M., Smith, P.A., Ivanov, I.V., 2013. A framework for grouping nanoparticles based on their measurable characteristics. Int. J. Nanomedicine 8, 45-56.

SCCS, 2012. Guidance on the Safety Assessment of Nanomaterials in Cosmetics. Scientific Committee on Consumer Safety, Brussels.

SCENIHR, 2007. Opinion on the Appropriateness of Existing Methodologies to Assess the Potential Risks Associated with Engineered and Adventitious Products of Nanotechnologies. Health \& Consumer Protection Directorate General of the European Commission, Brussels.

SCENIHR, 2009. Risk Assessment of Products of Nanotechnologies. European Commission, Scientific committee on emerging and newly identified health risks, Brussels.

Schneider, T., Brouwer, D.H., Koponen, I.K., Jensen, K.A., Fransmann, W., van DuurenStuurman, B., van Tongeren, M., Tielemans, E., 2011. Conceptual model for assessment of inhalation exposure to manufactured nanoparticles. J. Expo. Sci. Environ. Epidemiol. 1-14.

Semenzin, E., Lanzellotto, E., Hristozov, D., Critto, A., Zabeo, A., Giubilato, E., Marcomini, A. 2015. Species sensitivity weighted distribution (Sswd) for ecological risk assessment of engineered nanomaterials: the N-Tio2 case study. Environ. Toxicol. Chem.

Shatkin, J.A., 2008. Nanotechnology: Health and Environmental Risks. Boca Raton, Tylor \& Fransis.

Som, C., Nowack, B., Krug, H.F., Wick, P., 2013. Toward the development of decision supporting tools that can Be used for safe production and use of nanomaterials. Acc. Chem. Res. 46, 863-872.

Stone, V., Pozzi-Mucelli, S., Tran, L., Aschberger, K., Sabella, S., Vogel, U.B., Poland, C., Balharry, D., Fernandes, T., Gottardo, S., Hankin, S., Hartl, M., Hartmann, N., Hristozov, D., Hund-Rinke, K., Johnston, H., Marcomini, A., Panzer, O., Roncato, D. Saber, A.T., Wallin, H., Scott-Fordsmand, J.J., 2013. Research Prioritisation to Deliver an Intelligent Testing Strategy for the Human and Environmental Safety of Nanomaterials. Edinburgh.

Stone, V., Pozzi-Mucelli, S., Tran, L., Aschberger, K., Sabella, S., Vogel, U., Poland, C., Balharry, D., Fernandes, T., Gottardo, S., Hankin, S., Hartl, M.G.J., Hartmann, N., Hristozov, D., HundRinke, K., Johnston, H., Marcomini, A., Panzer, O., Roncato, D., Saber, A.T., Wallin, H., Scott-Fordsmand, J.J., 2014. ITS-NANO-Prioritising nanosafety research to develop a stakeholder driven intelligent testing strategy. Part. Fibre Toxicol. 11.

Subramanian, V., Semenzin, E., Hristozov, D., Zondervan- Van Den Beuken, E., Linkov, I. Marcomini, A., 2015. Review of decision analytic tools for sustainable nanotechnology. Environ. Syst. Decis. 35, 29-41.

Sun, T.Y., Gottschalk, F., Hungerbühler, K., Nowack, B., 2014. Comprehensive probabilistic modelling of environmental emissions of engineered nanomaterials. Environ. Pollut. $185,69-76$.

Tervonen, T., Figueira, J.R., 2008. A survey on stochastic multicriteria acceptability analysis methods. J. Multi-Criteria Decis. Anal. 15, 1-14.

Tervonen, T., Linkov, I., Figueira, J., Steevens, J., Chappell, M., Merad, M., 2009. Risk-based classification system of nanomaterials. J. Nanopart. Res. 11, 757-766.

Tiede, K., Boxal, A.B.A., Tear, A.P., Lewis, J., David, H., Hassellov, M., 2008. Detection and characterization of engineered nanoparticles in food and the environment. Food Addit. Contam. 25, 795-821.

Toropov, A.A., Leszczynski, J., 2006. A new approach to the characterization of nanomaterials: predicting Young's modulus by correlation weighting of nanomaterials codes. Chem. Phys. Lett. 433, 125-129.

Toropov, A.A., Leszczynska, D., Leszczynski, J., 2007. Predicting water solubility and octanol water partition coefficient for carbon nanotubes based on the chiral vector. Comput. Biol. Chem. 31, 127-128. 
Toropova, A.P., Toropov, A.A., 2015. Mutagenicity: QSAR - quasi-QSAR - nano-QSAR. MiniRev. Med. Chem. 15, 608-621.

Tuoriniemi, J., Cornelis, G., Hassellov, M., 2014. Improving the accuracy of single particle ICPMS for measurement of size distributions and number concentrations of nanoparticles by determining analyte partitioning during nebulisation. J. Anal. At. Spectrom. 29, 743-752.

Van Harmelen, T., Zondervan- Van -Den Beuken, E.K., Brouwer, D.H., Kuijpers, E., Fransman, W., Buist, H.B., Ligthart, T.N., Hincapié, I., Hischier, R., Linkov, I., Nowack, B., Studer, J., Hilty, L., Som, C., 2016. LICARA nanoSCAN-a tool for the self-assessment of benefits and risks of nanoproducts. Environ. Int. 91, 150-160.

Van Kesteren, P.C.E., Cubadda, F., Bouwmeester, H., Van Eijkeren, J.C.H., Dekkers, S., De Jong, W.H., Oomen, A.G., 2014. Novel insights into the risk assessment of the nanomaterial synthetic amorphous silica, additive E551, in food. Nanotoxicology 9, $442-452$.

Van Leeuwen, C., Vermeire, T., 2007. Risk Assessment of Chemicals: An Introduction. Springer, Dordrecht.

Van Ommen Kloeke, A.E.E., Gong, P., Ellers, J., Roelofs, D., 2014. Effects of a natural toxin on life history and gene expression of Eisenia andrei. Environ. Toxicol. Chem. 33, 412-420.

Walser, T., Gottschalk, F., 2014. Stochastic fate analysis of engineered nanoparticles in incineration plants. J. Clean. Prod. 80, 241-251.
Walser, T., Studer, C., 2015. Sameness: the regulatory crux with nanomaterial identity and grouping schemes for hazard assessment. Regul. Toxicol. Pharmacol. 72, 569-571.

Wigger, H., Hackmann, S., Zimmermann, T., Köser, J., Thöming, J., Von Gleich, A., 2015. Influences of use activities and waste management on environmental releases of engineered nanomaterials. Sci. Total Environ. 535, 160-171.

Yang, Y., Chen, Q., Wall, J.D., Hu, Z., 2012. Potential nanosilver impact on anaerobic digestion at moderate silver concentrations. Water Res. 46, 1176-1184.

Yokel, R. A, Florence, R. L, Unrine, J.M. Tseng M.T, Graham, U.M., Wu, P Grulke, E A Sultana, R., Hardas, S.S., Butterfield, D.A., 2009. Biodistribution and oxidative stress effects of a systemically-introduced commercial ceria engineered nanomaterial. Nanotoxicology 3, 234-248.

Yokel, R.A., Au, T.C., Macphail, R., Hardas, S.S., Butterfield, D.A., Sultana, R., Goodman, M., Tseng, M.T., Dan, M., Haghnazar, H., Unrine, J.M., Graham, U.M., Wu, P., Grulke, E.A., 2012. Distribution, elimination, and biopersistence to 90 days of a systemically introduced $30 \mathrm{~nm}$ ceria-engineered nanomaterial in rats. Toxicol. Sci. 127, 256-268.

Zalk, D., Paik, S., Swuste, P., 2009. Evaluating the Control Banding Nanotool: a qualitative risk assessment method for controlling nanoparticle exposures. J. Nanopart. Res. 11, 1685-1704. 